\title{
ASPECTOS DE LA VIDA BURGUESA EN \\ SANTA CRUZ DE LA PALMA A MEDIADOS DEL SIGLO XIX. \\ EL ABOGADO ANTONIO DE LAS CASAS LÓPEZ Y SU FAMILIA
}

\author{
José Eduardo Pérez Hernández* \\ Universidad de La Laguna
}

\section{RESUMEN}

El apellido De las Casas es ejemplo en la isla de La Palma de una burguesía que ha evolucionado, a lo largo de tres generaciones, de rústica y arrendataria de la oligarquía insular, en la segunda mitad del siglo XVIII, a urbana, comercial y dedicada a las profesiones liberales en el siglo XIx. Este artículo se apoya en la colección documental del fondo «Antonino Pestana Rodríguez» (El Museo Canario) para estudiar algunos aspectos de la vida social y privada del abogado Antonio de las Casas López y su familia a mediados del xix. Resulta un comportamiento del burgués caracterizado por la coexistencia, en cuestiones como el camino hacia el matrimonio, la promoción social y el honor de la familia, de actitudes mentales modernas junto a otras actitudes típicas de la sociedad del Antiguo Régimen.

Palabras clave: historia de la familia, historia de las mentalidades, burguesía comercial, profesión liberal, cartas de amor, pleitos de familia, Santa Cruz de La Palma, siglo xIx.

\section{ASPECTS OF BOURGEOIS LIFE IN SANTA CRUZ DE LA PALMA IN THE MID-19 th $C E N T U R Y$. THE LAWYER ANTONIO DE LAS CASAS LÓPEZ AND HIS FAMILY}

Abstract

On the island of La Palma, the surname De las Casas is an example of a bourgeoisie that has evolved, over three generations, from rustic and tenant farmers of the island's oligarchy, in the second half of the $18^{\text {th }}$ century, to urban, commercial and dedicated to the liberal professions in the $19^{\text {th }}$ century. This article is based on the "Antonino Pestana Rodríguez" documentary collection (El Museo Canario) to study some aspects of the social and private life of the lawyer Antonio de las Casas López and his family in the mid-nineteenth century. The result is a behavior of the bourgeois characterized by the coexistence, in matters such as the path to marriage, social promotion and family honour, of modern mental attitudes together with other typical attitudes of the Old Regime society.

KEYwORDs: history of the family, history of mentalities, commercial bourgeoisie, liberal profession, love letters, family lawsuits, Santa Cruz de La Palma, $19^{\text {th }}$ century. 
¡Lástima grande que no nos dejara siquiera una seria narración histórica de La Palma, de la que corren por ahí cronicones que tienen más de novela que de historia! Pero don Antonino, que fue periodista en sus buenos tiempos, no quiere escribir y se limita a preparar los materiales para que otros construyan.

«El homenaje a don Antonino Pestana». El tiempo: diario de la tarde (Santa Cruz de La Palma, 29 de febrero de 1928).

\section{INTRODUCCIÓN}

La disciplina Historia de la familia conoció un desarrollo espectacular a partir de 1950 de la mano, primero, de historiadores franceses, ingleses y norteamericanos, cuyas pautas siguieron después otras historiografías como la española. Así, pues, se han publicado multitud de estudios acerca de la familia en el pasado desde enfoques diversos: la economía, la demografía, el derecho y, por influencia de la sociología y antropología, los sentimientos y comportamientos, es decir, la Historia de las mentalidades ${ }^{1}$. En esta última y más reciente línea de investigación se encuadra el artículo que el lector tiene ante sí, que trata el tema de la burguesía y la familia en el siglo XIX.

Es bien sabido que el burgués descuella en la sociedad decimonónica liberal, pero no es menos cierto que cualquier caracterización suya ajustada a un molde ideal uniforme en lo económico, político e ideológico tropieza con la realidad del caso concreto. Lo han demostrado múltiples estudios prosopográficos locales, esto es, el análisis a fondo de un individuo, una familia o un grupo social reducido. Se llega así a ciertas conclusiones más o menos provisionales sobre su comportamiento que son el punto de partida para nuestro trabajo. Una burguesía de pequeńa ciudad portuaria vinculada al comercio, que no pierde la cara a la práctica del rentismo y a la inversión diversificada y segura, que propende a una cerrada endogamia y «donde la familia constituye el eje por el que discurre toda la actividad económica y desde donde se explica la fusión de intereses»².

En el análisis del burgués, la información con que cuenta el historiador decide la vía de investigación más adecuada. Cuando gran parte de la documentación que la sustenta es privada y referida a unos pocos individuos de una misma familia, se

hotmail.com.

* Licenciado en Geografía e Historia por la Universidad de La Laguna.E-mail: joseduph@

${ }^{1}$ Para una buena síntesis sobre la evolución historiográfica de la familia europea, con comentarios sobre las virtudes y defectos de las obras analizadas, véase MuÑoz López, Pilar. «La historia de la familia en la reciente bibliografía europea». Historia Social, n. ${ }^{\circ} 1$ (1995), pp. 145-155.

2 Fernández García, Antonio y Rueda Laffond, Juan Carlos: «La sociedad (I): los grupos sociales», en Jover Zamora, José María (dir.). Historia de España Menéndez Pidal; v. 38: Los fundamentos de la España liberal (1834-1900). La sociedad, la economia y las formas de vida. Madrid: Espasa Calpe, 1997, p. 138; y más ampliamente, pp. 127-140. 
presenta la oportunidad de ahondar en un caso concreto ${ }^{3}$, reconstruir parte de su vida cotidiana y analizarla en su contexto para descubrir en qué cosas se ajusta al modelo normativo y en cuáles lo contradice. Es la metodología de la vía nominal ${ }^{4}$ o de la microhistoria. También constituye el enfoque de la nueva historia cultural ${ }^{5}$, que ha prosperado como alternativa a la historia cuantitativa. Quiere ser una aproximación al modo de vivir, de pensar y de sentir del burgués de una pequeña ciudad no desde la frialdad de los datos seriales sino desde el oasis emocional del individuo y la familia a mediados del Ochocientos.

Santa Cruz de La Palma es el escenario de nuestra historia. La capital de la isla de La Palma tuvo brillante pasado renacentista que deja bella impronta en su fisonomía decimonónica. En el ecuador del xix la vieja ciudad conventual, dulcera y sedera se encuentra en transición hacia la nueva urbe burguesa de puerto franco, tiendas de comercio, espacios de recreo y profesiones liberales. El término municipal tiene 5641 habitantes y alrededor de 1200 edificios. Las tres calles principales, que se tienden rectas a lo largo del litoral marino (la calle Real de O'Daly y de Santiago unidas por un puente sobre el cauce de un barranco, y la Trasera), albergan las mejores viviendas y lo más granado de la sociedad. Además, Santa Cruz de La Palma concentra la inmensa parte de la riqueza imponible industrial y comercial de la isla (81,49 por ciento), sectores que suponen un tercio de la riqueza total del municipio capitalino; y este reúne casi la cuarta parte de la riqueza imponible insular ${ }^{6}$.

Aunque la vieja ciudad gozaba aún de fama en el exterior por su elaboración de dulces a partir de la caña de azúcar, los mejores cañaverales de La Palma, situados en Argual y Tazacorte desde la conquista castellana, acababan de echar el cierre en 1830 y 1840, respectivamente. De este modo llegaba a su fin el otrora álgido renglón azucarero del Quinientos insular. En esta zona la familia De las Casas, protagonista de estas páginas, comenzó su elevación social en la segunda mitad del siglo xviII. A este ascenso, de una generación de arrendatarios de un décimo de cańas, artesanos y traficantes de productos derivados de la cańa a otra de abogados, comerciantes y navieros afincados en la capital palmera, dedicamos el primer capítulo.

Dentro del marco familiar que nos ocupa, el segundo capítulo refleja la curiosa coexistencia de dos conceptos considerados antitéticos por gran parte de la

${ }^{3}$ La fuente orienta la obra de investigación. Un caso singular, como el nuestro, puede verse en: Pérez Barrios, Carmen Rosa. Los Alfonso Gorrin: un ejemplo de burguesía agraria en el sur de Tenerife en el tránsito del siglo XIX al XX. La Laguna: Benchomo, 2000. Pérez Barrios estudia en profundidad un fondo familiar encontrado en el Archivo Municipal de Guía de Isora, consistente en correspondencia privada y empresarial, libros de contabilidad, recibos y facturas, cuya naturaleza induce a la autora al análisis de las relaciones económicas en el seno de esta familia de la burguesía tinerfeña.

${ }^{4}$ Serna, Julio y Pons, Anaclet: "El nombre del burgués», en Bonamusa, Francisco y Serrallonga, Joan (eds.). La sociedad urbana en la España contemporánea. Barcelona: Asociación de Historia Contemporánea, 1994, pp. 83-87.

5 Bel Bravo, María Antonia: La familia en la historia: propuestas para su estudio desde la «nueva» historia cultural. Madrid: Encuentro, 2000, p. 70.

${ }^{6}$ Madoz, Pascual: Diccionario geográfico-estadistico-histórico de España y sus posesiones de Ultramar (1845-1850). Islas Canarias. Valladolid: Ámbito, Interinsular Canaria, 1986, pp. 158-162. 
historiografía sobre la burguesía ochocentista: el amor y el interés, que aquí aparecen de la mano en el enlace matrimonial del abogado Antonio de las Casas López y su prima hermana Petra de las Casas Lorenzo. Las relaciones amorosas entre primos no eran empero infrecuentes en el mundo burgués, pues éstos se encontraban a menudo en las ocasiones festivas o en los rituales de sociedad que reunían a toda la familia. Se tenían por vínculos fiables y formaban parte de las estrategias matrimoniales endogámicas de reproducción social para impedir la dispersión de la propiedad y mantener la integridad del patrimonio familiar ${ }^{7}$. Así, de ocurrir el enamoramiento, se producía en un ámbito estrecho y vigilado donde las posibles parejas eran más o menos las idóneas. Los jóvenes de este modo constreñidos podían elegir dentro de un pequeño círculo sin causar conflicto ni trastornar los planes matrimoniales de sus familias. El amor, surgido en un espacio geográfico compartido por intereses comunes y similitudes culturales y de sociabilidad, podía tolerarse ${ }^{8}$.

Pero ¿nuestros jóvenes protagonistas hablan desde el corazón? Petra, sin duda, sí; Antonio, no está tan claro. El lenguaje amoroso de él puede ser el dulce envoltorio bajo el que se encierra el cerebral interés. No es una afirmación sino una hipótesis. Antonio inicia su avance hacia Petra prácticamente en el momento en que se producen dos hechos trascendentales: uno, el padre de ella fabrica un barco para el tráfico canario-americano en el astillero de la ciudad, esto es, golosos beneficios en perspectiva; y, dos, antes de la conclusión del buque, este mismo padre fallece y su viuda e hijos varones se enfrascan en sacar a flote la empresa comercial. Esto quizá pudo permitir cierto margen de libertad a Antonio, deseoso de estrechar lazos familiares con esta prometedora sociedad mercantil, para actuar sin el férreo control del principal cancerbero de los intereses de las niñas De las Casas Lorenzo9. La estrategia epistolar con Petra (la más accesible o la que más le gusta de sus primas hermanas) logra el propósito de enamorar a la joven en secreto y apartarla para sí del mercado matrimonial. La relación por carta tendría así un posible componente de cálculo para mantener en la distancia la llama del deseo de un matrimonio ventajoso.

7 Arbelo García, Adolfo: Las mentalidades en Canarias en la crisis del Antiguo Régimen. Elites agrarias y comportamiento social en Tenerife (1750-1823). Tenerife, 1998, p. 28. En este sentido, dice Josef Ehmer: "Los objetivos de la endogamia social de las estrategias matrimoniales se hicieron más exigentes de lo que habían sido en siglos anteriores [...]. Las relaciones de parentesco desempeñaron un papel cada vez más importante en la creación de la endogamia social. Consecuentemente, en las clases más ricas y con propiedades el matrimonio entre parientes se hizo mucho más frecuente». Consúltese Ehmer, Josef: «El matrimonio», en Kertzer, David y Barbagli, Marzio (comps.). Historia de la familia europea; v. II: La vida familiar desde la Revolución Francesa hasta la Primera Guerra Mundial (1789-1913). Barcelona: Paidós Ibérica, 2003, p. 428.

${ }^{8}$ Gay, Peter: La experiencia burguesa. De Victoria a Freud; v. II: Tiernas pasiones. México D.F.: Fondo de Cultura Económica, 1992, p. 11; así mismo, Ehmer, Josef: «El matrimonio», op. cit., p. 454.

9 Cabe recordar el reforzamiento del patriarcado, del control del hombre sobre la esposa e hijos, en los códigos civiles de la Europa burguesa y liberal del siglo XIX. Consúltese Casey, James. Historia de la familia. Madrid: Espasa-Calpe, 1990, p. 164. 
La vida doméstica del matrimonio de Antonio y Petra de las Casas es el tema del tercer capítulo. Nuestro abogado tiene en casa su despacho de trabajo y conocemos algo de su actividad letrada. Pero no se limita al desempeño de su profesión; diversifica en lo posible la economía familiar: administra bienes ajenos, vigila los réditos del barco familiar de la carrera americana, introduce la cochinilla en sus tierras y alquila los bajos de su vivienda. Parece seguir el modelo clásico del burgués ahorrador. Y otro lugar común: la complicada relación con el servicio doméstico; es asombroso el trasiego de criadas en un periodo de tiempo tan corto. Como familia de reciente llegada al estatus burgués, podría pensarse que practica con fervor los valores normativos de clase del mérito individual, la capacidad intelectual y la igualdad de oportunidades, pero no es así; recurre a menudo a las relaciones de lealtad personal, de padrinazgo, de amistad y de parentesco, propias de la vieja corrupción antiguorregimista $^{10}$, a la hora de satisfacer objetivos y aspiraciones.

Conviene recordar que el ámbito de la vida privada constituyó un tema prohibido para la historiografía hasta el último cuarto del Novecientos. Por pudor, el historiador no lo consideraba de su competencia y lo excluía de sus líneas de investigación. Fue esa otra revolución francesa, la de la escuela historiográfica de Annales, la que reivindicó para el análisis histórico la esfera de lo privado como modo de entender la sociedad en todas sus dimensiones. Annales sostiene que para conocer en profundidad una sociedad es preciso entrar «en un mundo tan difícil de captar como es el de las pautas de conducta que lo rigen y el de los valores que lo sustentan, llegando hasta el análisis de los pormenores de la vida cotidiana, aun cuando ello suponga un problema de fuentes y de método»" ${ }^{11}$.

El cuarto capítulo nos devuelve a las relaciones familiares extensas, pero sujetas al conflicto. La familia De las Casas López se ve sacudida por el oprobio de las deudas y nuestro protagonista trata de evitar la pérdida de patrimonio y el descrédito a costa de otro escándalo: la división familiar ${ }^{12}$. Y el mismo resultado se produce cuando duda de la honestidad empresarial de su tía y primos a cuenta del reparto de los beneficios del bergantín San Miguel. Ambos pleitos darían de sí para un breve tratado de mentalidades.

Los protocolos notariales del Archivo General de La Palma, los legajos judiciales de la sección Audiencia del Archivo Histórico Provincial de Las Palmas, los padrones de habitantes, juicios de conciliación y reparto de contribuciones del Archivo Municipal de Santa Cruz de La Palma y los libros sacramentales de la Parroquia Matriz de El Salvador han sido fuentes de consulta importantes para el tema

${ }^{10}$ Cruz, Jesús: Los notables de Madrid: las bases sociales de la revolución liberal española. Madrid: Alianza, 2000, pp. 174-178.

11 Langa LaORga, María Alicia: Tradición y modernidad en la configuración social de Europa (1800-1850). Madrid: Síntesis, 1994, p. 98.

12 Al burgués decimonónico acecha el riesgo cierto de la desintegración de su fortuna, la fragmentación de su patrimonio y, en último término, la desaparición del nombre. Ante esta terrorífica perspectiva solo caben la unidad y la solidaridad del grupo familiar. Consúltese SERNA, Justo y Pons, Anaclet. «El nombre del burgués», op. cit., p. 108. 
que nos ocupa. Pero este artículo no sería factible sin el recurso fundamental del archivo personal. Formando parte de los papeles de procedencia familiar palmera del fondo Antonino Pestana (El Museo Canario de Las Palmas de Gran Canaria), se hallan más de ciento treinta cartas de amor inéditas que intercambiaron, desde 1838 hasta 1845, el estudiante de leyes Antonio de las Casas López, residente en La Laguna (Tenerife), y su prima Petra Luisa de las Casas Lorenzo, domiciliada en Santa Cruz de La Palma. La documentación permite profundizar en los nuevos aspectos de la sensibilidad burguesa en el campo del amor vivido e inspirado en la literatura romántica. El mismo custodio guarda otro documento de notable provecho para el presente estudio: una suerte de cuaderno dietario con apuntes diversos sobre las actividades domésticas, económicas y profesionales del matrimonio De las Casas.

Para tratar de dilucidar si estamos ante un caso excepcional de correspondencia amorosa en una centuria que generalmente resuelve los enlaces matrimoniales burgueses en términos de conveniencia, parece oportuno detenernos en la figura del coleccionista documental palmero Antonino Pestana Rodríguez ${ }^{13}$. A diferencia de otros eruditos de la historia insular que recopilaron muchos datos con vistas a su conocimiento, preservación y divulgación durante la segunda mitad del XIX y primeros años del $\mathrm{xx}^{\mathrm{I4}}$, Pestana no se concentró solamente en la historia con mayús-

${ }_{13}$ Antonino Pestana Rodríguez (Santa Cruz de La Palma, 1859-Las Palmas de Gran Canaria, 1938) nació como Antonio de San Juan Rodríguez, hijo natural del comerciante José Pestana Ramy y de María de las Nieves Rodríguez López, cuyos apellidos rectificó legalmente por los verdaderos en 1880. La tipografía y el periodismo ocuparon buena parte de su tiempo en la juventud, mientras que la masonería, en la cual alcanzó el más alto grado, fue un abrazo de casi toda su vida. En los años interseculares lo encontramos en el pueblo de Garafía, casado con su maestra de escuela María Antonia Lorenzo Díaz, donde ejerció de secretario municipal y de juez de paz, y donde tuvo la desgracia de perder a dos de sus hijos pequeños en el incendio de su casa en las navidades de 1896. Las llamas consumieron también su archivo, que contenía ejemplares muy valiosos de autógrafos y documentos históricos, y una habitación que servía de museo de «recuerdos arqueológicos palmeros». La última etapa en la administración civil la desempeñó en la Delegación del Gobierno en La Palma: de oficial de segunda clase a secretario. El diario El tiempo, de 29 de febrero de 1928, con motivo de la inminente jubilación de Pestana, publicó el artículo «El homenaje a don Antonino Pestana", retratándolo como "paciente recopilador de crónicas y noticias, de documentos, libros y periódicos» relativos a su isla natal. Es «una historia viva de Canarias y tal vez la mejor historia pública y privada de La Palma, pues al través de los años, ha ido compulsando datos, comprobando hechos, rectificando fechas y recogiendo opiniones y teorías que luego, al pasar por el tamiz de su inteligencia, han sufrido una seria depuración». Consúltese para más información: Poggio Capote, Manuel y Hernández Correa, Víctor J. El oficio de cronista en Santa Cruz de La Palma. [Santa Cruz de La Palma]: Cabildo Insular de La Palma, 2018, pp. 69-79; asimismo, Pérez García, Jaime. Fastos biográficos de La Palma. Santa Cruz de La Palma: Real Sociedad Cosmológica, Caja General de Ahorros de Canarias, 2009, p. 324.

${ }^{14}$ Fundamentalmente, dos: Juan Bautista Lorenzo Rodríguez y Pedro J. de las Casas Pestana. Véanse Poggio Capote, Manuel y Hernández Correa, Víctor J. El oficio de cronista en Santa Cruz de La Palma..., op. cit.; Régulo Pérez, Juan. «El cronista de La Palma Juan Bautista Lorenzo Rodríguez: época, vida y obra", en Lorenzo Rodríguez, Juan Bautista. Noticias para la historia de La Palma; v. I (3. ${ }^{a}$ edición). Santa Cruz de La Palma: Cabildo Insular de La Palma, 2010, pp. XIIIlX; Pérez Hernández, José Eduardo. «Introducción», en Lorenzo Rodríguez, Juan Bautista. 
culas de La Palma. Su afán por investigar la lengua y costumbres de los aborígenes palmeros, la historia menuda, la etnografía y la pequeńa literatura le confiere un perfil más romántico que el de sus colegas; no el de un visionario capaz de anticipar los derroteros a largo plazo de la historiografía occidental, sino el del coleccionista curioso que todo lo reúne. Sin duda tiene un loable propósito como sus compañeros, y de hecho compone algunos manuscritos, aunque publica menos, pero diríase que, por la varia naturaleza de sus piezas ${ }^{15}$, en ocasiones de íntimo recreo, se entrega a una morbosa diversión en familia o entre amigos con la exhibición y lectura de algunas «joyas» de su colección. Las cartas de amor, por ejemplo.

Aparte de la larga serie de misivas que veremos en este trabajo, Antonino Pestana atesoró en su archivo algunas otras cartas amorosas sueltas de diversa autoría palmera del siglo XIX. ¿Por qué este tipo documental llama su atención? ¿Cómo llegan las cartas a sus manos? Quizá accedió a la correspondencia de los jóvenes De las Casas por vínculo familiar posterior, tal vez relacionado con la testamentaría de María Dolores de las Casas López a partir de 1910 (véase el epílogo de este artículo). Pero las otras cartas revelan una querencia no casual, puede incluso que una búsqueda interesada. ¿Acaso le resultan llamativas por lo inusual de la manifestación del amor en la planificación matrimonial de aquellos tiempos? La respuesta está posiblemente entre los viejos papeles privados de quién sabe cuántas familias de nuestros días con antepasados acomodados, porque nos inclinamos a creer que esta clase de correspondencia no era tan extrańa como pudiera parecer en el Ochocientos.

\section{DE LAS CASAS: EL ASCENSO SOCIAL}

El apellido De las Casas lo encontramos en la isla de La Palma, en el lugar de Los Llanos, al menos tres generaciones atrás de nuestros protagonistas. En su testamento de 26 de marzo de 1822, don Antonio de las Casas Acosta, hijo de José de las Casas y Petra de Acosta, representa a la burguesía agraria consolidada mediante su vínculo con la oligarquía insular poseedora de las tierras de regadío en el Valle de Aridane. Por espacio de trece años fue arrendatario de un décimo de cańas en el pago de Tazacorte, propiedad de dońa Ana Tello de Eslava, viuda del terrateniente don Juan Massieu Fierro. Una vez casado adquirió alrededor de una decena de terrenos en la jurisdicción de Los Llanos y fabricó su casa terrera con cubierta de tea y teja en Las Quintas de Argual, junto al camino real, además de poseer por compra otra casa terrera en la calle Real llanense. De su matrimonio con Petra Álvarez nacieron cinco hijos: Antonio, Miguel, Tomasa (casó con don Vicente Sosa Taño,

Noticias para la historia de La Palma; v. Iv. Santa Cruz de La Palma: Cabildo Insular de La Palma, 2011, pp. XI-XXII.

15 Para comprender la variedad de esta colección documental, Véase Rodríguez MACARIO, José Iván. «Ordenación, clasificación y conservación de la colección documental de Antonino Pestana Rodríguez (El Museo Canario)». Cartas diferentes: revista de patrimonio documental, $\mathrm{n} .{ }^{\circ} 13$ (2017), pp. 73-93. 
también de la incipiente burguesía agraria del Valle), Laura y José (marchó a América y allí se perdió su rastro) ${ }^{16}$.

Para subrayar con la honorabilidad la incipiente fortuna obtenida y para elevar a su familia en la escala social, don Antonio de las Casas Acosta sentó una información de limpieza de sangre de sus padres (1803); era lo típico: cristianos viejos, limpios de mala raza, libres de todo castigo del Santo Oficio, etc.; y aseguró que emparentaban con "personas de distinción", citando en este sentido el apellido Acosta ${ }^{17}$ de su madre, el cual anteponía al primer apellido materno (Ortega) ${ }^{18}$. Así, pues, en el ocaso del Antiguo Régimen, como en el siglo XVI, una familia de nuevos ricos seguía haciendo del linaje una cuestión de honor; vestirse con un ropaje de aparente prestigio como credencial para el inminente asiento familiar entre lo más granado de la noble ciudad de Santa Cruz de La Palma. En fin, desde cambiar el orden de los apellidos hasta la manipulación del árbol genealógico para esconder los orígenes dudosos y convertir en buena sangre lo que los modelos definían como mala, "con dinero resultaba más sencillo parecer limpio»" ${ }^{19}$.

Don Antonio de las Casas Álvarez, el primogénito, comenzó su carrera mercantil traficando con los productos derivados de la caña de azúcar, especialmente pan de gofio y melado que le suministraba su padre en calidad de arrendatario del décimo antedicho ${ }^{20}$. Pasó a residir en Santa Cruz de La Palma, en un inmueble de

16 Archivo General de La Palma, Protocolos Notariales (AGP, PN), escribanía de José Manuel Salazar, Santa Cruz de La Palma, 1822, ff. 137 v.-143 v.

17 Acosta era una antigua familia de noble cuna del reino de Portugal, que se hacía descender, por línea bastarda, de los soberanos de aquel país. Era por tanto un apellido aprovechable. El caso de la familia De las Casas no es el primero en la isla en sacar pecho de firmarse Acosta. En 1647, a poco de establecerse en Santa Cruz de La Palma, los Acosta del lugar de Puntallana también habían recurrido al mecanismo de la información de limpieza de sangre para probar la supuesta calidad de su linaje. Dio resultado a uno de sus vástagos establecido en América y en continuo ascenso social, Gaspar Mateo de Acosta, quien en 1697 preparó a su vez otra información de limpieza claramente fraudulenta para aupar aún más alto en la escala social a su único hijo varón. Véase FernÁndez de Bethencourt, Francisco. Nobiliario de Canarias (obra ampliada y puesta al día por una Junta de especialistas); v. II. La Laguna (Tenerife): Juan Régulo, 1954, p. 523; PÉrez García, Jaime: «Una nobleza falseada: los Acosta de Puntallana». Revista de estudios generales de la isla de La Palma, n. 2 (2006), pp. 757-766.

${ }_{18}$ ES35001 AMC, AP- 03879: Copia autorizada de la información de limpieza de sangre y genealogía de don Antonio de las Casas (1804). AMC, AP: Archivo de El Museo Canario, Fondo Antonino Pestana.

${ }^{19}$ Contreras Contreras, Jaime: «Linajes y cambio social: la manipulación de la memoria». Historia social, n. ${ }^{\circ} 21$ (1995), p. 118.

${ }^{20}$ ES35001 AMC, AP- 04273, 04274 y 04275: Cuentas llevadas entre don Antonio de las Casas Acosta y su hjo don Antonio de las Casas Álvarez. Consúltese asimismo: ES35001 AMC, AP- 03968: Libro de cuentas de Antonio de las Casas (1797-1803); 03984: Cuentas del arrendamiento de un décimo de cańas en Tazacorte, por don Antonio de las Casas (1833); 05149: Documentos contables correspondientes a la familia De las Casas (1803-1847); 05266: Documentación diversa de cáracter económico relacionada con la familia De las Casas (1793-1840). En el acta del Concejo palmero de 15 de julio de 1793 se cita a «... un rapadurero llamado Antonio de las Casas...» [Archivo Municipal de Santa Cruz de La Palma (AMSCP), Actas, Caja 698-1-1]. Documenta la dedicación 
la calle Real (luego O'Daly) que le cediera su tío Pedro de las Casas en 1807, y abrió dos tiendas, una de ropa y otra de víveres, en las cuales invirtió ocho mil pesos. Además del inmueble y las tiendas de comercio, De las Casas Álvarez, que había subrayado el lustre de su apellido accediendo al cuerpo militar con el cargo distintivo de subteniente de milicias provinciales ${ }^{21}$, trajo 6500 pesos en efectivo, un crédito de casi mil pesos que le adeudaba su padre y algunos terrenos en La Galga a su matrimonio con María Dolores López Monteverde, hija del escribano capitalino don José Mariano López Aubert, efectuado el 8 de septiembre de $1814^{22}$. Procedió después a su consolidación patrimonial: dio término a la reforma y ampliación de su vivienda en su parte posterior, en la que gastó 3896 pesos, y la liberó de tributos; compró tres fincas en la demarcación capitalina entre 1823 y 1832 (dos en el barranco de Maldonado y otra en La Dehesa con sus respectivas casas para el veraniego solaz; una de las de Maldonado la fabricó de su peculio), amén de tres terrenos más en Breña Alta en los años treinta ${ }^{23}$. Su primer hijo, Antonio María Manuel José Joaquín Francisco de Paula Ruperto de las Casas López, nació el 27 de marzo de 1815. Siguieron otros nueve: Miguel, José María, María del Pino, Francisco, Antonia, Tomás, María de los Dolores, Juana y Federico ${ }^{24}$; algunos de ellos desempeñarán un papel en las páginas siguientes. Fue también edil en el ayuntamiento de la capital insular.

Desde noviembre de 1826 hasta abril de 1842, don Antonio de las Casas Álvarez, ya capitán del regimiento de milicias provinciales, llevó el registro de sus compras de aguardiente a cosecheros de toda la isla. Los apuntes permiten conocer nombres de productores, altibajos de precios año a año, época en que se efectuaban tales operaciones (a menudo durante los segundos semestres) y condiciones de compra ${ }^{25}$. Llegó a ser uno de los mayores exportadores a América y, en 1834,

familiar no solo al tráfico de los productos de la caña pero también a su elaboración. La rapadura es un postre tradicional de la isla de La Palma, por lo común de forma cónica, cuyos ingredientes más importantes son la miel de cańa y el gofio.

${ }^{21}$ «... si bien constituye el pertenecer a estos cuerpos en tal categoría [oficiales de milicias] un distintivo honorífico para el linaje y existen cédulas reales que previenen para la provisión de estos empleos la condición de Hijodalgo, en la práctica no tuvo efecto este requisito...». Véase Peraza DE Ayala, José. «El elemento nobiliario en la vida social de Tenerife, Gran Canaria y La Palma», en FernÁndez de Bethencourt, Francisco. Nobiliario de Canarias..., op. cit., pp. xxx-xxxi.

22 Archivo de la Parroquia de El Salvador (APES), Matrimonios, Libro 8, f. 165.

23 AGP, PN, escribanía de Antonio López Monteverde, Santa Cruz de La Palma, 1840, f. 335-338 v.; testamento de don Antonio de las Casas Álvarez, fechado el 9 de octubre de 1840. La casa familiar que se cita es la actual Casa Duque, calle O’Daly, 20. Véase Pérez García, Jaime. Casas y familias de una ciudad histórica. La calle Real de Santa Cruz de La Palma. Santa Cruz de La Palma: Cabildo Insular de La Palma, Colegio de Arquitectos de Canarias, 1995, p. 171.

24 APES, Bautismos, Libro 17, ff. 232, 261 y 295; Libro 18, ff. 31 y 53.

25 Por ejemplo, Dionisio Carrillo vendió 20 pipas de aguardiente a Antonio de las Casas en 1833, a razón de 30 pesos la pipa, con la condición de que el comprador lo tomase de su bodega de Los Sauces y pagase el «fleto», mientras Carrillo abonaría «las averías». En octubre de 1835, Carrillo vendió 10 pipas de su cosecha de dicho año a De las Casas por el precio de 50 pesos la pipa, cuyo monto total el comprador habría de pagar en abril del ańo siguiente. El mismo vendedor hizo otra 
abonaba por subsidio mercantil mucho más dinero que nadie ${ }^{26}$. Al final de su vida mantenía el establecimiento de ropas en la calle Real de la capital, donde puso a despachar a sus hijos Miguel y Francisco. Había conseguido una posición holgada para los suyos en el seno de la burguesía comercial insular, lo que le permitió dar una carrera universitaria a sus hijos Antonio y José María. Los quería ver abogados para beneficio de la familia, como así fue, pues bien sabía lo que era sufrir y perder litigios injustamente ${ }^{27}$.

La pillería sufrida por el progenitor incubaría un sentimiento de agravio familiar que caló hondo en los hermanos De las Casas López, quienes como abogados asumieron que la mejor defensa era el ataque y pasaron a ser expertos cazadores de derechos sobre capellanías vacantes o perdidas en el tiempo. Indagaron así en los archivos, elaboraron genealogías y aplicaron sus conocimientos legales al incremento del patrimonio familiar, todavía proindiviso, ambicionando los bienes de aquellas viejas fundaciones religiosas a las cuales podían aspirar de alguna manera y que se encontraban en el candelero por el proceso desamortizador ${ }^{28}$. Contaron para ello con su hermano Miguel, quien cambió el mostrador por el púlpito, más parece por interés que por vocación, y en su calidad de presbítero reclamó por vía judicial los derechos a determinadas capellanías para la familia ${ }^{29}$. Los letrados desplegaron parecida actitud, sin muchos escrúpulos, a la hora de enfrentar los pleitos de los acreedores contra su familia por las deudas paternas, pero esta vez ello tuvo consecuencias internas negativas, como se verá más adelante.

Por su parte, don Miguel de las Casas Álvarez, casado el 24 de abril de 1808 con María de la Encarnación Lorenzo, destacó como exportador e importador en el tráfico entre Canarias y América, aunque en menor medida que su hermano. Al final de su vida decidió costear la fabricación de un bergantín con el presumible propósito inicial de participar en el lucrativo negocio de la exportación de emigrantes a Venezuela. Cuando su propietario murió, en mayo de 1838, el San Miguel estaba todavía a medio hacer pero su viuda, mujer decidida y emprendedora, tomó las riendas de los intereses de la familia: concluyó la fábrica del barco con la madera legalmente

venta de 10 pipas a De las Casas en 1836, pero ahora por 80 pesos la unidad. Consúltese ES35001 AMC, AP- 04141: Libro de compras de aguardiente (1826-1842); así mismo, AMC, AP- 03983.

${ }^{26}$ AMSCP, Caja 420, Contribución Industrial (1834).

27 Según se desprende de su testamento, el vendedor de una de las fincas de Maldonado le ocultó que estaba gravada por cierta capellanía, con cuyo capellán pleiteó sin resultado, pagando al final el censo y las decursas de muchos años que adeudaba otra persona.

${ }^{28}$ Pérez Hernández, José Eduardo. Las personas de valer. El mundo de la burguesía en La Palma en el siglo XIX. [Santa Cruz de La Palma]: Cabildo Insular de La Palma, 2007, pp. 62-63 y $187-188$.

${ }^{29}$ Archivo Histórico Diocesano de Tenerife, Capellanías, Legajos 261 (6), 293 (9.2) y 507 (33). Se trata de las capellanías fundadas por Margarita de Santa Cruz y su hijo Bartolomé de Abreu; Josefa del Jesús Felipe, Ángela Francisca Monterrey (viuda del alférez Francisco Pérez Volcán) y Rosa María Volcán Monterrey; el alférez Luis de Morales; y Francisco González Sicilia y su esposa Juana Rodríguez, por cuyos derechos Miguel de las Casas López opositó en la Diócesis de Tenerife en la década de 1850 . 
obtenida en los montes de Santa Cruz de La Palma, Los Sauces y Puntallana; reflotó la decadente tienda de mercería de su marido y, con la excepción de Manuel de las Casas Lorenzo, orientado al sacerdocio, colocó a sus otros hijos varones al frente de ambos negocios, dirigiendo sus actividades y supervisando las cuentas que aquellos le presentaban ${ }^{30}$. Se establecía que la burguesa era una sociedad hecha por hombres para hombres, donde la mujer, representada como un ser inocente, puro y espiritualmente elevado, no debía tomar parte en «los sucios manejos de la política o los negocios ${ }^{31}$. Una vez más, al descender de lo general al detalle de lo particular, saltan las costuras del pensamiento dominante.

Don José Miguel de las Casas Lorenzo (1809-1878), el hijo mayor, fue el primer capitán del San Miguel en expediciones a La Guaira, cargado de emigrantes hasta los topes, al comenzar la década de $1840^{32}$. Eran años de migración de canarios a la América del Sur, en buena parte debido al efecto llamada desde la joven república venezolana ${ }^{33}$, pero también en la región emisora por la fuerte crisis humanitaria desatada en las islas de Lanzarote y Fuerteventura en ocho ańos seguidos de malas cosechas. El pingüe negocio para los armadores y capitanes de los barcos isleños de la carrera americana llevó al exceso por codicia. Los barcos se despacha-

${ }^{30}$ APES, Matrimonios, Libro 8.․, f. 123; AMSCP, Aprovechamientos forestales, Caja 778-3, licencia de corte de madera de 17 de julio de 1838; AGP, PN, escribanía de Antonio López Monteverde, Santa Cruz de La Palma, 1869, ff. 648-649 v.; testamento cerrado de dońa María de la Encarnación Lorenzo, con fecha de 27 de julio de 1848. Se da la circunstancia de que varios de sus hijos (José Miguel, Antonio y Miguel de las Casas Lorenzo, además de Manuel que, como quedó dicho, era clérigo) permanecían solteros en el hogar familiar de la calle Trasera, número 23, bien entrada su edad madura.

${ }^{31}$ Leites, Edmund. La invención de la mujer casta. La conciencia puritana y la sexualidad moderna. Madrid: Siglo XXI, 1990, p. 136.

32 «... El dos de este mes entre cuatro y cinco de la tarde dieron las velas al viento del puerto de La Palma, los dos barcos llamados el San Miguel y el Voluntario con dirección a La Guaira, y según me han escrito personas fidedignas, llevaron a su bordo, como en pellas de pescado, mil ciento treinta personas de ambos sexos; $;$ mil ciento treinta personas! ${ }$ Mil ciento treinta personas, en dos barcos de pocas toneladas!...»; consúltese Apóstata. «Remitido». El daguerrotipo (Santa Cruz de Tenerife, 24 de abril de 1841), p. [1].

33 A partir de 1831, la primera república de Venezuela ofreció pasaje gratuito y lotes de tierras baldías a los inmigrantes canarios expresamente, pues apreciaban su honradez, laboriosidad, aclimatación y buen conocimiento del trabajo del campo desde la época colonial. Estas condiciones óptimas llegaron en una situación insular de crisis, proletarización campesina y excedente de fuerza de trabajo. En 1840, en sintonía con los intereses de la terratenencia venezolana, la política inmigratoria estableció subvenciones a la introducción de jornaleros canarios bajo contrata por los hacendados, quienes sufragaban a los empresarios de inmigración el flete, alojamiento y manutención en el puerto de llegada del inmigrado captado en el archipiélago. Luego, una vez en la hacienda cafetalera, el isleño devolvía con su trabajo el coste que había ocasionado. Los armadores y capitanes de barcos canarios sacaban una suculenta tajada de este tráfico humano. En 1841 llegaron a Venezuela 2260 emigrantes canarios bajo contrata (992 de ellos mujeres); en 1842, 1150; en 1843, 1558... Se contabilizan más de doce mil emigrados canarios a esta república sudamericana entre 1832 y 1846. Véase Macías Hernández, Antonio M. Revisiones y provocaciones. Diez artículos de historia económica de Canarias. [Santa Cruz de Tenerife-Las Palmas de Gran Canaria]: Idea, 2003, pp. 231-266. 
ban y emprendían viaje con más pasajeros de los que podían conducir y alimentar a su bordo decentemente ${ }^{34}$.

Dos hijos más de la viuda Lorenzo se turnaron en la comandancia del barco en posteriores viajes a Cuba. Uno, Miguel, fallecido en 1888, fue el marino más destacado de los hermanos De las Casas: alférez de fragata condecorado con la cruz de primera clase del mérito naval con distintivo blanco en 1878, varias veces ayudante de marina de la isla y capitán de su puerto. El otro, Nicolás (1820-1901), era el genio polifacético de la familia, pronto inclinado a la vida en tierra en tanto que arquitecto naval (Amparo, Ninfa de los mares), prohombre en la lucha política local (alcalde de su ciudad natal), ideólogo de reformas urbanas (presidente de la sociedad constructora La edificadora palmense) y escultor de algún mérito, pues suya es la talla de la Virgen de la Capilla, perteneciente a la Venerable Orden Tercera, y la menos lograda del Señor del Huerto, en la iglesia de San Pedro de Breńa Alta en la actualidad, al parecer realizada en apenas quince días, en 1862, auxiliado por Francisco Figueredo, ayudante primero del Cuerpo de Ingenieros de Caminos, Canales y Puertos, a la sazón residente en la capital insular con motivo de las obras del muelle, quien pintó la imagen ${ }^{35}$.

Quedaron, siempre en tierra, Antonio de las Casas Lorenzo (¿̨-1880), dueño de una tienda de géneros de segunda clase con un dependiente a su cargo, amén de teniente de alcalde de la capital al filo de 1850, y Andrés de las Casas Lorenzo (¿?-1881), también comerciante con establecimiento en la ciudad insular.

La viuda Lorenzo murió a la edad de 82 años, el 31 de marzo de 1869, pero por lo menos hasta la fecha en que testó (1848) llevó las riendas de la economía familiar con presunción de cuentas saneadas y aplicando el lema mosquetero entre sus hijos. La larga vida del barco familiar es prueba de ello; con sus aproximadamente cuarenta años de servicio, el bergantín San Miguel, de 157 toneladas, fue el más longevo con diferencia de los navíos salidos del astillero insular en el primer Ochocientos. Aunque la viuda trató de evitar toda posible discordia en la firma «Las Casas Hermanos» para el futuro, retirando la mejora del tercio y quinto de sus bienes a quienes alterasen con reclamaciones la buena armonía del grupo, no lo logró. Precisamente la suspicacia de su yerno Antonio de las Casas López con las cuentas del San Miguel (lo veremos en otro capítulo), daría al traste en cierto modo con el anhelo de tan extraordinaria mujer.

Presentadas las familias de los protagonistas principales que serán de las páginas siguientes, entramos ahora en el periodo que acabó por estrechar todavía más el vínculo que ya las unía; esto es, la relación amorosa de Antonio de las Casas

34 Galván Rodríguez, Eduardo. Elorigen de la Autonomía Canaria. Historia de una diputación provincial (1813-1925). Madrid: Ministerio para las Administraciones Públicas, 1995, pp. 76-77.

35 "Crónica del país». Eco del comercio: periódico literario, de noticias e intereses materiales (Santa Cruz de Tenerife, 26 de abril de 1862), p. [2]. Así mismo, Rodríguez-Lewis, J.J. «La Semana Santa de Santa Cruz de La Palma: una aproximación diacrónica», en Poggio Capote, Manuel y Hernández Correa, Víctor J. (eds.). Consummatum est. L aniversario de la fundación de la Cofradía del Santo Sepulcro. Breńa Alta (Isla de La Palma): Cartas Diferentes Ediciones, 2007, pp. 61-63. 
López con su prima hermana Petra Luisa Venancia de las Casas Lorenzo, un año mayor que él (había nacido en Santa Cruz de La Palma, el 18 de mayo de $1814^{36}$ ), a través de la correspondencia privada que ambos cruzaron desde 1838 hasta 1845 .

\section{CARTAS DE AMOR}

San José de Breña Baja, verano de 1838. En la casa de campo de la familia De las Casas López, «Dolores» ${ }^{37}$ escribía sendas cartas el 10 y 15 de agosto a Petrita Luisa, su "querida y adorada amiga», quien veraneaba con los suyos en el pago capitalino de La Dehesa de la Encarnación, a varios kilómetros de distancia. Cómplice en realidad de su hermano Antonio, bajo el aparente lenguaje apasionado de la amiga del alma ${ }^{38}$ subyacía un mensaje de amor de aquél para su prima. La primera misiva, con cierre lacrado, era una solapada manifestación de su amor y el deseo de ser correspondido cuanto antes, decía, "para tener el gusto de oirte la contestación que ha de suavisar y mitigar el dolor de mi ausencia». Parece que a pocas semanas de su vuelta a Tenerife, donde cursaba estudios universitarios desde $1834^{39}$, Antonio de las Casas López trataba previamente de asegurar la todavía secreta relación amorosa con su prima. De ahí el apremio por su respuesta:

36 APES, Bautismos, Libro 17, f. 208 v.

37 María de los Dolores de las Casas López (Santa Cruz de La Palma, 1826-1910), hermana de nuestro protagonista. Contrajo matrimonio con Severiano González Guerra, escribano de actuaciones judiciales y experto genealogista, en 1864. Tras fallecer trágicamente su único hijo y heredero, y no teniendo otros herederos forzosos, hizo testamento dejando todos sus bienes al Hospital de Dolores en 1907, reservando un legado para la atención anual de personas necesitadas. Consúltese Pérez García, Jaime. Fastos biográficos de La Palma..., op. cit., p. 93.

${ }^{38}$ El historiador Alain Corbin apunta: «La elección de la amiga del corazón constituye un episodio importante de la vida de la adolescente. Las madres favorecen el desarrollo de estas amistades duraderas entre muchachas serias y totalmente sinceras. Porque esperan que la solidez de semejante vinculación, antítesis de la frivolidad de las amistades mundanas, será uno de esos puntos fijos que permitirán que su hija se oriente en la existencia. [...] Las «mocitas casaderas» se dedican a intercambiar una copiosa correspondencia, así como a hacerse recíprocas visitas. [...] Por supuesto, las primas juegan a veces el papel de interlocutoras predilectas». Véase Corbin, Alain: «Entre bastidores", en Duby, George y Ariès, Philippe (dirs.): Historia de la vida privada, vol. 8: Sociedad burguesa: aspectos concretos de la vida privada. Madrid: Taurus, 1991, pp. 216-217.

39 Antonio de las Casas López comenzó la carrera de leyes en la Universidad de Canarias en el curso 1838-1839, pero posiblemente habría completado antes tres o cuatro años de Filosofía y Letras, pues en el testamento paterno, que citamos páginas atrás, se fija en 1834 su entrada en la Universidad. Obtuvo al término del primer año de Leyes (derecho natural y legislación universal) la nota de "notablemente aprovechado", la misma que sus compañeros palmeros de curso, que lo eran su hermano José María de las Casas López, Manuel y Esteban Abreu Luján y Miguel Silva (José Bosio Corral no se examinó hasta octubre). Antonio Ferrer y Lemos iba un curso por delante. En segundo curso, 1839-1840, los hermanos De las Casas lograron el «sobresaliente»; un curso por detrás venían sus paisanos José Antonio Hernández Guerra, Vicente García González y Domingo Calderón, quienes acababan de completar tres años de Filosofía y Letras [Boletín oficial de Canarias (Santa Cruz de Tenerife, 7 de agosto de 1839 y 13 de julio de 1840)]. 
... Mañana sin falta la espero para lo cual irá por ahí una muger de este campo, a quien se la puedes entregar: veremos si cumples este precepto que te impone tu amiga, y exige la misma amistad que reina entre las dos; de lo contrario ya sabes que mis agravios son eternos, y el causármelos es una de las mayores crueldades de que no debo ni puedo creer sea capas el bello corazón de mi amiga.

Consciente del lenguaje subtextual que por el momento camuflaba la relación entre ambos ${ }^{40}$ y del complaciente papel de chica que despertaba al amor por primera vez, Petra, con bastante peor ortografía, recibió favorablemente el exigente ruego planteado por su «Doloritas amiga mia»:

... Tu carta produjo en mi una censacion estraordinaria [...] todo hasta mi corazon le hiso bariar tu tierna declaracion, y en recompensa de tus bellos sentimientos: conosco y debo decirte que tu amiga ha qui y en todas partes lleba un alma cencible y amorosa [...]; será que habrá descubierto todo el poder sinpático que media entre las dos, yo desearía que se consolidasen estos cimientos; me sería muy grato que me escribieras siempre y largo; yo parto a la ciudad mañana o pasado mańana, de allí podré con más facilidad espresar mis centimientos. A Dios, en ti ce enciera mi cariño, ciendo mi corazon libre asta de aora, esto es si tu manifestacion es ingenua ${ }^{41}$.

Antonio le volvió a escribir en la última semana de agosto, pero esta vez con la firma de su nombre de pila e iniciales de sus apellidos, para suplicarle que se apiadara de su tormento y le abriera su corazón, porque sin su amor «... aborresco mi existencia y tan solo deceo la muerte como el termino de mis males» ${ }^{42}$. De lo que parece deducirse que Petra Luisa, sujeta al ritual social exigido a las señoritas honestas y virtuosas, había puesto objeciones a la relación en ciernes con el fin de probar la formalidad de su primo. No era una mera pose sin importancia. Dejarse llevar entrańaba el riesgo de un escándalo. Precisamente uno de los de padre y muy señor mío tenía lugar en el entorno familiar más cercano del pretendiente de Petra. Las relaciones secretas del escribano público Pedro López Monteverde, tío de Antonio, con la joven Juana Felipe Carmona, hija del marino y naviero Buenaventura

40 A priori, en las estrategias matrimoniales concertadas del siglo XIx, las relaciones entre primos eran normales. ¿Por qué pues este sigilo? Cabe suponer que las relaciones de ambas familias emparentadas tan estrechamente no eran las más cordiales en este momento. También que la muerte del padre de Petra exigiera por su parte y la de su familia el luto largo y riguroso acostumbrado, durante el cual no debía ni pensarse en iniciar públicas relaciones de noviazgo.

${ }^{41}$ ES35001 AMC, AP- 02231 y 02812. La segunda carta de «D...» avanzaba confiadamente (nótese cómo en algunas palabras se descubre la verdadera identidad de su autor): «Adorada amiga Petrita Luiza: [...] yo tampoco, querida mia, ni puedo ni querré separarme [de ti] [...] me dices de ese poder simpático que te une a tu amiga: por lo que hace a mi, bien persuadido estoi de que nací para amarte [...] yo no me consideraba tan digno de merecer en ese grado tu bello corazón [...]. Una feliz casualidad me proporcionó el darte a conocer el carińo, o mejor diré, el excesivo amor que ya hacía tiempo te profezaba mi sensible pecho [...] con el laconismo propio de la pacion [...] tu amiga te jura una amistad y un carińo eterno que llevará hasta el mismo sepulcro, en donde descanzando, suspirará quizá por su tierna, por su cara y dulse amiga».

${ }_{42}$ ES35001 AMC, AP- 02232. 
Felipe Carmona, supusieron al fin la acumulación contra el primero de dos causas criminales por rapto y estupro instruidas en el Juzgado de Primera Instancia de La Palma en 1839, pero con el acusado en busca y captura por haberse fugado de noche a la isla de Tenerife ${ }^{43}$.

Ante la resistencia de Petra, para Antonio era obligado entonces insistir, extremar sus ruegos y expresar las fatales consecuencias de aquella frialdad ${ }^{44}$. Antonio adoptaba el papel de amante desgraciado y celoso que juzgaba las reticencias de Petra, expresadas en sendas conversaciones entre ambos en aquel mes de agosto de 1838, como preferencia por cierto joven "M...» (seguramente Manuel Mendoza Morales, quien a los pocos años formalizó su noviazgo con Antonia, hermana de nuestra protagonista). Sin embargo de conceder con humildad que su amada era muy dueña de elegir y de amar a quien quisiera, trataba de disipar las dudas de la joven por medio de una persuasiva reflexión acerca del amor y de la felicidad como premio para dos personas mutuamente atraídas ${ }^{45}$.

43 En la orden de busca y captura se daban las señas del escribano Pedro López Monteverde, de 33 ańos: estatura regular, nariz gruesa, ojos pardos, pelo colorado, cara regular, color blanco y pecoso, barba poblada y colorada, vestido decente. Si el enamoramiento (al menos por parte de ella) jugó un papel en los acontecimientos que llevaron al nacimiento de una hija en común y al matrimonio entre ambos, muy posterior, el 27 de mayo de 1859 en la ermita de la Caridad de Tacoronte (Tenerife), lo cierto es que al cabo de algunos años todo había terminado según se desprende del testamento de su única hija, Faustina Petra López Felipe, otorgado en Santa Cruz de La Palma en 1873. Faustina confesaba haber sido testigo en su niñez de una fraudulenta artimaña notarial de su padre, con la complicidad del escribano de la otorgación Domingo Mora, para engañar a su madre, que creía firmar un declaratorio de los bienes aportados al matrimonio por su marido cuando en realidad firmaba un documento público de renuncia a los bienes gananciales por parte de la esposa, engaño que descubrió algún tiempo después cuando, "por desavenencias que ocurrieron entre ambos, tuvo motivo de ir á imponerse en el protocolo». Al morir Pedro López Monteverde en la capital palmera el 5 de febrero de 1871, sin hacer testamento, vivía en la calle O’Daly, n. ${ }^{\circ} 8$, mientras que su esposa Juana habitaba en la calle San José, n. ${ }^{\circ}$ 2; casi en el otro extremo de la misma ciudad. Consúltese AGP, PN, escribanía de Cristóbal García Carrillo, Santa Cruz de La Palma, 1871, ff. 161 y 165; escribanía de Melchor Torres Luján, Santa Cruz de La Palma, 1873, v. II, ff. 1.421-1423 v., testamento de doña Faustina Petra López Felipe, fechado el 19 de febrero de 1873; además, AMC, AP- 01871: Autos del pleito promovido por don Buenaventura Felipe Carmona contra don Pedro López Monteverde por rapto y estupro de su hija Juana Felipe Carmona (1836-1845); así mismo: Boletín oficial de Canarias (Santa Cruz de Tenerife, 30 de octubre de 1839), pp. 704-705.

${ }_{44}$ Sobre los usos amorosos en la burguesía insular del Ochocientos, véanse Pérez HerNÁNDEZ, José Eduardo. Las personas de valer..., op. cit., pp. 159-184; Idem. «Acerca de los usos amorosos en el Diecinueve insular: el diario críptico de Severiano González Guerra (1849)». Revista de estudios generales de la isla de La Palma, n. 0 (2004), pp. 365-395.

45 «... Y supuesta esta verdad ¿por qué consideras que seremos desgraciados amandonos? ¿Creerás porque estaremos por algun tiempo separados, y que esto mismo puede causar el olvido? ¡Ah! no lo creas; ni la mas larga distancia, ni los ańos es capas de borrar nuestro amor, si nuestro amor es verdadero; esas leyes eternas con que la naturaleza une a sus criaturas entre si, son constantes y respetadas por todos los tiempos y por todas las cosas ¿Y que temes mi primita, mi amiga? ¿No has penetrado ya mi eterna afición, para que dejes esos temores, y consagres tu cariño al mismo que te da su corazón? ¡Ah! habla de una vez, dime que me amas [...]. Si algún inconveniente hay respecto a mi, si mis declaraciones no han sido claras y terminantes, y si consideras que me ha faltado alguna 
Dos meses más tarde -octubre de 1838- Antonio pudo embarcar para Tenerife con una promesa de amor eterno de su prima. Una vez allí empezó por consolarla dada la obligada separación: pedía que no sufriera, que se distrajera y divirtiera con moderación, pues confiaba en ella porque «sé lo que eres y por lo mismo tu estas esenta de cualquier prueba, que exigiria otro menos seguro de tu amor que yo». Solo le imponía escribir con cada barco, "pero con la circunstancia de que me manifiestes tus sentimientos con la mayor ingenuidad y que te estiendas todo lo posible, en lo que conoceré si tienes ó no gusto de hablar jay! de escribir á tu amigo» (29 de octubre de 1838$)^{46}$.

Antonio cayó enfermo de gripe nada más llegar a La Laguna, pero solo cuando lo peor hubo pasado comunicó la verdad a su amada. De nuevo, de la mano, el amor y la muerte: «si, mi amada, mil veces me figuré que perecía, y en mis congojas tu sola ocupabas mi corazón, mi memoria recordaba a la vez tus dulses encantos y mis ojos no hacían sino llorarte» (12 de noviembre de 1838$)^{47}$.

Un año después, Antonio de las Casas López había sustituido "Querida amiga" por "Mi amor, mi adorada P...». Pero llegó también la primera crisis de pareja debida, al parecer, a la irregularidad del servicio de correos: se reprocharon su falta de amor por no recibir cartas en mucho tiempo. El estudiante de leyes se mostró celoso y exigente, ahora sí, con el deber de Petra hacia su novio ausente (13 de octubre de 1839):

... desde hoy en adelante, no has de mirar á M..., ni á ningun otro, has de acortar tus diverciones, has de hacer todos los sacrificios que puedas y con los que des á conocer á la gente soy yo el unico á quien amas tanto precente como aucente; pues desde el momento en que tenga pruebas para cerciorarme de lo contrario, desde ese mismo te aborreceré y quedan nulas aquellas dos palabras ${ }^{48}$.

No era otra cosa que la queja de rigor del enamorado celoso, ritos de paso en los cuales la relación no peligraba. En el post scríptum de la misma carta le pedía: "conserva con mucho cuidado esta y las demas para berlas la noche de nuestra boda".

Petra parecía halagada antes que ofendida por semejantes reacciones de Antonio, pues escribió el 5 de febrero de 1840: «Mi amado yo no etenido amal tus quejas por que tambien yo me habia quejado, y sabes aquien, al Cielo alli donde me declaraste tu amor por la vez primera y juraste cer mio asta la muerte apesar de mi oposicion por que es verdad que en tonces no amaba». Pero si en aquella misiva se despedía con "Adios Adios mi idolatrado amor», en marzo la joven recayó en el resentimiento porque Antonio no escribía; lo trataba de usted («Mui señor mio») y

otra en que manifieste afirmativamente la responsabilidad de tu amor, habla, dime lo que puedas exigir de mi, que yo gustoso bajo mi firma, y jurandote por lo mas sagrado que haya en los cielos y en la tierra, me comprometo a cumplirtelo...»; véase ES35001 AMC, AP- 02232.
46 ES35001 AMC, AP- 02233.
47 ES35001 AMC, AP- 02234.
48 ES35001 AMC, AP- 02235. 
pedía explicación de su «indiferencia tan notable» ${ }^{49}$. La situación volvió a su cauce cuando aquél confesó que había pasado por similares dudas respecto de su amada: otra vez los retrasos del correo y el ansia de tener cartas uno del otro. Cuando por fin llegaba la deseada carta era el alivio del tormento de la duda. El 29 de abril de 1840, Petra escribió: «la tube por mucho tiempo aprietada ami corazon, y en seguida llevandola amis labios le di dos ardientes besos, tanto cuanto me es querido el objeto aquien los daba»; y añadía, sumisa, la promesa de no mostrarse fría nunca, pues «asta fingir sabré por agradarte, [pese al sufrimiento] que me dan las laguneras... yo aprecio mucho y como es debido el interés que te tomas en enseńarme el modo como deba amartes ${ }^{50}$.

La razón de estas continuas recaídas en temores y reflexiones melancólicas no era otra que la ausencia, en cuyos periodos el amor y la muerte surgían siempre inseparables, esto es, el amor traicionado conducía al sepulcro. Así, en diciembre de 1840, Petra contó a su novio sus penas en una carta que parece parafrasear algún pasaje de novela romántica ${ }^{51}$. No siginifica que Petra fuese una lectora voraz (su mala ortografía no indica tal cosa), pero sí que tuviese a mano la literatura de moda que necesitaba para expresar sus sentimientos. La moral católica decimonónica establecía que una muchacha honesta no debía leer novelas de amor, pues era considerado un peligroso veneno que socavaba el statu quo burgués de los arreglos matrimoniales entre las familias basados en el cálculo y el interés ${ }^{52}$. Sin embargo, como en otros aspectos que se verán, nuestra joven no estaba sujeta al modelo. El amor romántico apasionado era algo más que un ideal prohibido.

49 ES35001 AMC, AP- 02377 / 02378.

${ }^{50}$ ES35001 AMC, AP- 02379.

51 «Oh! si descubrieses que nace de que yo te amo mil veces mas que vos me amais ámi pareceme que naci para obedecerte y adorarte asolas me culpo por la pacion que me inspiras pero delante de ti siento un impulso natural a creerme dilicuente cuando te ago infelis de donde biene querido amigo este inperio que egerceis sobre mi no puedo vivir sin verte; ${ }_{j} H$ Habeis creido que ecsistiria un istante despues de perderos! que escasa idea os he dado pues de mi amor, cuando ningun poder humano ni ninguna orden vestra podria hacerme soportar la vida si cesases de amarme quien enjugaria mis lagrimas y que me importaria el amor de otro si estos no me an enseńado como tu amor solo tu ocupas mi alma [...]. Adios mi bien soy tuya asta la muerte». Consúltese ES35001 AMC, AP- 02381. A comienzos de la década de 1840, el hombre más rico de la isla, el hacendado Felipe Massieu y Tello de Eslava, poseía una notable biblioteca romántica en su casa de Santa Cruz de La Palma. No es descabellado suponer que las familias más o menos adineradas de la burguesía comercial y naviera de la capital insular pudieran recibir novelas y revistas de actualidad en los tornaviajes de sus barcos. $\mathrm{Y}$ que directa o indirectamente impregnados en ellas se hicieran notar en la correspondencia y en los álbumes privados de sus hijos. Una generación romántica insular, entonces todavía en la infancia, eclosionó en la década de 1850, dejando testimonio de su inquietud literaria en diversos textos manuscritos así como en la prensa provincial. Esta pléyade de jóvenes talentos fue como una llamarada, bella pero efímera, pues pronto quedó diezmada por la mortal tuberculosis pulmonar. Véase Pérez Hernández, José Eduardo. «El poeta Fernando Cabrera de la Nuez: un majorero en el cenit romántico de La Palma (1855-1859)», en VIII Jornadas de Estudios sobre Lanzarote y Fuerteventura (1997). Arrecife de Lanzarote: Cabildo Insular de Lanzarote, 1999, v. I, pp. 387-413.

52 De Giorgio, Michela. «El modelo católico», en Duby, George y Perrot, Michelle (dirs.). Historia de las mujeres en Occidente, vol. IV: El siglo XIX. Madrid: Taurus, 1993, p. 196. 
Como era la costumbre, Antonio de las Casas López pasaba los veranos en La Palma y volvía a La Laguna en octubre para seguir sus estudios. El contacto personal dominaba sobre el escrito en las vacaciones de estío. La escritura consistía en breves notas de Petra, enviadas mediante mensajero, por las cuales citaba a su novio para verse de día o de noche, ella puesta en la ventana de su cuarto y él al parecer en el exterior de la casa.

Cuando su «adorado amante» partía para la universidad lagunera, Petra sufría mucho en los días siguientes. El 24 de octubre de 1841:

Mańana querido mio me boy para el canpo no por que yo decee distraerme pues mi mayor gusto es pensar en ti, si no por que el ayre libre del canpo la tranquilidad las costumbres cencillas y agradables aquel trato amable que la misma naturaleza en seña a los que viven en el podran en cierto modo acér llebadero mi destino [...] yo no puedo allar un momento de reposo mi corazon lleno de agitaciones no puede contenerce dentro de mi y tiene necesidad de desahogarse ${ }^{33}$.

Antonio debió de sentirse complacido por estas pruebas de sufrimiento amoroso de su amada, aunque seguía el guion que le correspondía de contener la pena de aquella recurriendo -también él- al poso que en su espíritu dejaban los finales trágicos de los amores literarios del Romanticismo. El 20 de noviembre siguiente:

Mi adorada P. trata de cuidarte de no dar entrada en tu pecho al dolor, la melancolia y todas las afecciones tristes que se apoderan en tales casos de un amante desdichado para conducirle al sepulcro; mas no, no, mi querida tu me darás el gusto de vivir tranquila [...] y esperando el dia feliz de vernos ${ }^{54}$.

La asociación del amor y de la muerte que vemos a cada paso en esta relación epistolar por parte de ambos jóvenes, como quedó dicho, se inspiraba en el romanticismo literario en boga ${ }^{55}$, en especial en Petra, cuyas cartas, extensas y sentimentales, tendían a la confesión de sus interioridades, mientras que las de Antonio, lacónicas casi siempre, hablaban menos desde el corazón.

Cada cierto tiempo, Petra se retiraba al campo para recuperar el ánimo y la salud y nutrirse y ponerse "gorda», que tanto gustaba a su novio de acuerdo con el ideal masculino de mujer atractiva en el mil ochocientos ${ }^{56}$. Petra Luisa asumía el papel de la futura esposa que todo hombre decimonónico querría para sí (ella lo lla-

53 ES35001 AMC, AP- 02382.

54 ES35001 AMC, AP- 02241.

55 El análisis de un corpus de correspondencias íntimas de la primera mitad del siglo XIX en Francia revela la presencia de este lenguaje de la pasión exaltada. Así, «El «amor enloquecido» hace gimotear; los celos adoptan las formas de la demencia; la enormidad del sentimiento engendra la tentación de morir». Consúltese Corbin, Alain. «Entre bastidores», op. cit., p. 226.

56 Carnes mullidas, caderas redondas, senos abundantes, tejidos bien alimentados..., así era la mujer 10 de la época para el perfecto desempeño de las funciones propias de su naturaleza reproductora y del cuidado de los niños y enfermos. Véase Knibiehler, Yvonne. «Corazones y cuerpos», en Duby, George y Perrot, Michelle (dirs.): Historia de las mujeres en Occidente..., op. cit., v. Iv, p. 322. 
maba educación y delicadeza en una mujer). Trataba de ser siempre complaciente. Se mostraba enamorada y entregada a su amado hasta el delirio: "A Dios mi bien, mi anelo mi placer mi Dios mi todo... soy tuya» (5 de diciembre de 1841); si Antonio pedía que le contara sobre los asuntos electorales en La Palma, ella se extendía en ellos y los comentaba "aunque no es lisito á las mugeres ablar de cosas politicas" ${ }^{57} ; \mathrm{y}$ cuando aquel le envió un vestido, ella escribió (7 de enero de 1842): «me quedo no mucho de mi gusto en quanto á la moda. Beseme todo el pecho y como puede gustarme ha mi eso ${ }^{58}$; por lo demas esta bueno y sobre todo el color». En otra ocasión -9 de febrero de 1842-, aseguró que aquellos carnavales eran los más aburridos de su vida: «si tu estuvieras aquí quantas veses te pintaría y jugaría contigo»; pero fingía estar enferma para no salir al salón de su casa a recibir a las máscaras, porque aunque quisiera no podría divertirse sin tenerlo a su lado ${ }^{59}$.

Más tarde, en cartas de 26 y 28 de marzo de 1842, Petra lamentó sufrir reproches de ingratitud e infidelidad de Antonio (tras llegar a Tenerife algunos barcos de La Palma sin cartas de su novia), cuando, le aseguraba, apenas había salido en Semana Santa y ni siquiera acudido al Teatro; que desde que leyera tan duras acusaciones en su carta:

... no he podido enjugar mis ojos [...] dejaria la vida con gusto solo por que una misma tumva en serrase mi cuerpo y el de mi amante pero a menos de esto no creas que me muero tan pronto [...] por quererte mucho tenia una tristeza tan grande que ni aun quería ver á nadie pero ya estoy buena [...]. Objeto amado de mi Corazon: [...] el que ama no desconfia y mas cuando tu sabes que no he querido anadie como á ti...60.

Otra vez el amor dramatizado a la moda romántica. Para que Antonio disipara sus últimas dudas y exigencias, el 7 de abril de 1842 se confesó extensamente evocando la angustia amorosa por que había pasado en los años que duraba la relación ${ }^{61}$. Remataba la misiva con un toque de celosa resolución: «Maldita sea esa Uni-

57 Nicole Arnaud afirma: «La exclusión de la vida política del sexo femenino es contemporánea de la expulsión del pueblo: ambos molestan al nuevo orden burgués que se instala. El discurso médico y religioso desarrolla este miedo, que volvemos a encontrar en los textos jurídicos, a que las mujeres se vuelvan incontrolables si acceden al poder de decisión». Consúltese ArNaud-Duc, Nicole. "Las contradicciones del Derecho», en Historia de las mujeres en Occidente..., op. cit., v. IV, p. 93.

58 «Hacia mediados del siglo [xix], la buena salud recibe carta de ciudadanía. Por la noche se exhiben las redondeces en escotes carnosos y lechosos. Para ofrecer a las miradas masculinas un busto amplio...». Consúltese Knibiehler, Yvonne. «Corazones y cuerpos»..., op. cit., p. 322.

59 ES35001 AMC, AP- 02384 / 02387.

${ }^{60}$ ES35001 AMC, AP- 02388 / 02389.

${ }^{61}$ «... ¡Dios de mi vida! ¡Tan culpable es este amor, va para cinco ańos que no tengo en mi corazon mas que, un pensamiento, el amor, ni mas que, un deseo, el amor, ni mas que, un nombre, el tuyo, cuando me miro á mi misma no veo mas que a ti, siempre tu y nada mas que tu, en mi alma esta tu imagen, ni puede ser otra cosa! ¡Cinco ańos ha que, te amo y como es posible que, con tanta facilidad como á ti te parece pueda uno olvidarse, y mas cuando tu á mi no me has hecho ningun mal ni yo á ti tampoco. Boy ablarte con la confiansa que, mereses: en los primeros meses de tu par- 
bersidad que me roba lo mejor, lo mas querido. No quiero pensar en esto, por que entonces no se logra mi intento que, es estar gorda para que ninguna te guste mas que yo».

La frágil salud de Petra de las Casas Lorenzo se evidencia en sus cartas de amor. Es una joven de oronda figura, propensa a sufrir cólicos y estados depresivos. De lo primero es ejemplo lo que contó a su novio el 21 de mayo de 1842: «... yo mi amor estube muy mala y en toda mi enfermedad no pensaba si no que no bolvia a verte que es lo que sentía, pues vierate yo y morir despues, pero con unas bentosas sargadas que me pusieron en el estomago y un purgante, estoy mejor ${ }^{62}$. De lo segundo, tenemos pruebas constantes: esos cuadros de aguda melancolía que padeció durante su relación amorosa por la ausencia del ser amado y por los malentendidos que ello provocaba. Sus estancias en La Dehesa y en Miraflores se las planteaba a manera de curas de salud. En aquella época la buena salud se asociaba a la gordura, así que para Petra la obesidad constituía un motivo de orgullo. El 19 de junio de 1842, señaló: «... he difrutado de mucha salu ... porque me he puesto mui gruesa que nadie me conose con los frecuentes biages al canpo» ${ }^{63}$. Quería estar espléndida cuando regresara Antonio en las vacaciones. Y como no había podido enviarle una décima escrita por su onomástica, postróse ante el san Antonio que poseía para suplicar la gracia de ver pronto a su amado ${ }^{64}$; sin embargo, cuando supo que los estudiantes universitarios retrasarían un mes su llegada, nueva recaída y vuelta a La Dehesa «...a ver si me distraigo pues estoy muy triste» ${ }^{65}$.

tida, padesi tanto que, es inposible esplicarte á veses se me oprimia el corazon que ni aun podia respirar nadie consolaba mis penas por que nadie sabia la causa de ellas, tu no sabes por que no lo puedo decir si no algun dia, entonces veras tu si era sensible mi situacion y si mi angustia de bia ser grande; pero á ora pienso en ti del modo mas alagueño que, te he de ver y tener á mi lado muy presto, que me quieres mucho, que yo solita soy acreedora á tu cariño, y que, las ingratitudes que, ha cada paso me hases no es mas que, amor, deceando tanto como yo verte...». Esta carta parece que no figura en la nueva clasificación de fondos del Archivo de El Museo Canario. Consúltese ES35001 AMC, AP- 02390 / 02392.

62 ES35001 AMC, AP- 02393.

${ }_{63}$ ES35001 AMC, AP- 02394.

${ }^{64}$ La imagen de san Antonio de Padua, taumaturgo de la caridad y protector de los niños, es una de las advocaciones de santos más presentes en el hogar burgués decimonónico en La Palma. Las devociones caseras eran un culto fundamentalmente femenino, que la Iglesia católica potenciaba como parte de esa feminización del catolicismo que se pretendía un baluarte contra el avance de la secularización. Véase Pérez Hernández, José Eduardo. Las personas de valer..., op. cit., pp. 260-261.

65 "La mujer del siglo XIX es una eterna enferma», asegura Yvonne Knibiehler, «la opinión corriente y la de muchos médicos achaca la «debilidad» de la «naturaleza femenina» a una causa biológica que se supone eterna y universal y que amenaza con alimentar un fatalismo insuperable». Pero, en realidad, en la mujer burguesa, «las penas y decepciones, la postración moral y el disgusto de vivir son consecuencia de condiciones más generales»: el confinamiento en espacios cerrados privados de aire y de sol, la falta de ejercicio físico encorvadas sobre los trabajos de aguja, etc. [KNIBIEHLER, Yvonne. «Corazones y cuerpos», op. cit., pp. 329-331]. La casa de campo, como queda patente en el caso de Petra de las Casas, constituye una tabla de salvación para quienes pueden permitírselo. Aunque entonces se incurre en otro mal, la alimentación desequilibrada por exceso, o sea, apunta- 
Hacia finales de 1842 una supuesta rival apareció en escena. Las cartas permiten entrever que, apelando a ciertas «leyes sociales», Antonio disimulaba su relación con Petra. Tanto así que nuestro estudiante, aparte de pedirle a ella adoptar en sus misivas un seudónimo masculino y el tono de dos amigos que se escribían, por temor a la intercepción del correo, se dejaba ver con otra mujer en público. Petra, como es natural, sufrió una explosión de celos. El 17 de noviembre de 1842: “¡y quien es esa muger! que tu obsequias en público y quien es esa muger la mas despreciable, tanto por su fisico como por sus prendas morales.... ${ }^{66}$.

Antonio quiso justificarse explicando que aquella mujer era una joven despechada en amores que se aferraba a él (un antiguo pretendiente) para vengarse de otro exnovio y a quien vaticinaba un trágico final de suicidio por sus "extravios» y su «loco amor». En seguida, cambiando de tema, para aquietar a Petra la animaba a aprender a tocar el piano que sus hermanos traerían a la vuelta de la última expedición del bergantín San Miguel: «distraete con esto, y llega a ser una buena maestra para que me des el gusto de oirtelo tocar, y que aun despues me enseñes tu a mi...» (29 de diciembre de 1842) ${ }^{67}$.

Las cartas posteriores no volvieron a mencionar el asunto de la aparente rival, por lo que es presumible fuera una tormenta pasajera.

En las primeras semanas de 1843, Antonio, amoscado porque habían llegado varios barcos sin traer cartas de Petra y porque oyera rumores sobre ella por otros medios, retomó su posición de juez severo y celoso de los movimientos de su novia: «... tu muy contenta, muy gorda, con mucho gusto, recibiendo máscaras, en grandes comitrages con tunantes, tocando el piano con Rami ${ }^{68} \ldots$ una muger tan

lar la obesidad en la falsa creencia de ser un signo de buena salud. Este erróneo criterio resultará a la postre fatal para nuestra protagonista.

${ }^{66}$ «... Dices que las leyes sociales te prohiben quererme publicamente; pues yo no puedo entender esto esplicamelo tu; no es nuestro amor el mas puro y mas santo que áya habido jamas. No mi bien no quiero alucinarme es por que amas ó mas bien adoras a esa muger, que tan bil é indebidamente o cupa mi lugar [...] yo sufro los mayores martirios con tu tanto dicimulo que me cuesta para verte andar mendigando tus mas precisos pasos [...] no enseńes esta ni ninguna de las mias a nadie; y menos a esa muger no quiero que sepa que es superior ami, si acaso te llegare algun dia acer indiferente á rojalas a las llamas». Esta carta parece no figurar en la nueva clasificación de fondos del Archivo El Museo Canario. Consúltese ES35001 AMC, AP- 02399 / 02400.

${ }^{67}$ Dice Anne Higonnet: «Eran pocas las chicas burguesas que no aprendían a tocar el piano o el violín, a cantar, a dibujar o a usar la acuarela. Se consideraba que esas habilidades artísticas [...] eran cualidades que refinaban la sensibilidad de una niña y la hacían socialmente atractiva...». Véase Higonnet, Anne: «Las mujeres y las imágenes. Apariencia, tiempo libre y subsistencia», en Historia de las mujeres en Occidente..., op. cit., v. IV, p. 279.

${ }^{68}$ Pedro Ramy Torres, pequeño-burgués cuarentón de ascendencia francesa e ideas progresistas, fue invitado a la casa de la familia De las Casas Lorenzo a probar y afinar el nuevo piano para las hermanas Antonia, Petra y Basilia. El enfado de Antonio tenía que ver con la admisión en el hogar de su novia de dicho Ramy, a quien tildaba de «relajado», así como de otros hombres solteros (dijo con sorna: «lo que falta es que entre toda la ciudad»), pero también por el insensato tren de vida que a su juicio se permitía aquella familia sin pensar en el ahorro para afrontar posibles tiempos difíciles en el futuro. Desaprobaba ambas cosas porque, en su opinión, los desacreditaba ante la sociedad, y amenazaba con romper sus relaciones con Petra si no se le ponía freno. El nerviosimo de 
ocupada y tan distraida, cómo ha de pensar en un triste estudiante aucente...» (22 de enero de 1843). Cinco días después Petra aclaró los rumores que pudiera escuchar, reiterándole su amor:

Mi querido: [...]. Sobre lo que me dices de R. una sola vez lo he visto tocar que fue el dia de ańo nuevo. Como tu sabes es muy antigua la costumbre de visitarnos en dias señalados y con el pretesto de dar los dias a Manuel $^{69}$ aunque el no acostumbraba vino a tocarlo por saber si era bueno; pero que desorden podia haber en una sala en que estaban las personas de mayor categoría y que sería una mala crianza si una señorita se levantara del canapé; yo no encuentro una razon para ecimirnos de esta antigua costumbre, ni para despreciar los ocequios de personas bien nacidas que no bienen a las casas si no a visitar con la mayor etiqueta. Esos libertinos y comilonas no an tenido nunca cabida en casa de mis padres; tu creeras que bino R. a finar el P. y se encontró solo en la sala que fue menester llamar a uno de los muchachos para que no digera que lo habian dejado solo. No quiero decir que le huimos a el hombre pues cada uno bien sabe con quien trata si no que era temprano y no podimos salir, esto es para que tu veas como levantar mentiras [...]. Quien te dijo a ti esas cosas fue el bobo de Silva que estubo el dia de año nuevo por la noche aquí [...]. No me incomodan tus consejos pero cuando son infundados padesco mucho [...]. Soy tuya asta la muerte... ${ }^{70}$.

Más adelante, el 18 de marzo de 1843, Petra Luisa volvió a la exaltada invocación romántica a la muerte, de inspiración literaria, por el prolongado silencio de Antonio:

... nada puede cer mas cruel que tu ingrato silencio, aboresco mi vida y si llega el sueńo apagar el dolor que me mata al despertar esclamo igran Dios! para que tor-

Antonio tenía quizá otra motivación añadida. En una casa con varias jóvenes casaderas, como eran Petra y sus hermanas, el piano era algo más que un instrumento de esparcimiento. Podía jugar el papel de lugar de encuentro y de diálogo amoroso y servir al propósito de los arreglos matrimoniales. En ocasiones el piano revelaba a los demás el estado del alma de una joven enamorada: «Bajo los dedos inocentes de la jovencita ignorante, el teclado traduce pulsiones que el lenguaje sería incapaz de expresar». Véase Corbin, Alain. «Entre bastidores», op. cit., pp. 188 y 190.

${ }^{69}$ Manuel de las Casas Lorenzo (Santa Cruz de La Palma, 1811-¿̨?), segundo hijo de Miguel de las Casas Álvarez y María de la Encarnación Lorenzo. Aparte de su hermano Simón (muerto prematuro), fue el único de los hijos varones que no se dedicó al comercio o la navegación, pues abrazó el sacerdocio. Pero parece que fue más producto del imperativo familiar que de una vocación verdadera. Cuando se le cita en la carta de Petra estaba apartado de su ministerio; según Sebastián Remedios, vicario insular, porque «no celebra ni oye misa ni tiene cosa que se paresca a eclesiástico» (1844), y ni siquiera vestía el traje propio de su estado. De las Casas aducía que arrastraba cierta enfermedad crónica desde 1839, a causa de cuya mala salud los médicos le prohibían beber vino y vestir la ropa talar (de ahí que no oficiase la misa), y que estaba presto para volver a gozar misa. El vicario Remedios y el obispo Luis Folgueras no parecían muy convencidos, pero estuvieron conformes en que aquel era recuperable. Así las cosas; Folgueras le devolvió la licencia para celebrar misa por un año (1845). [Archivo Histórico Diocesano de Tenerife (AHDT), Documentación por Pueblos, 63 (8)].

${ }_{70}$ Esta carta no parece figurar en la nueva clasificación de fondos del Archivo de El Museo Canario. 
nar a ver la luz si no tengo amante y el amor me abrasa ${ }_{¡} \mathrm{O}$ noche encantadora! noche dulce si fueres eterna para mi seria mucho mas grata, perdon, mi dulce amigo, hay momentos deceo se acabe mi amarga escistencia, porque tu no me has amado nunca... ${ }^{71}$.

Solamente reproches encendidos para ablandar el temperamento de su novio, pues no parecía dudar ahora de su lealtad amorosa. Antes bien, Petra sospechaba otra vez que las cartas de su amante eran interceptadas por el nuevo administrador de correos, Celestino del Castillo, por lo cual propuso cambiar los seudónimos de los sobres (24 de marzo de 1843). Ambos sentían ciertas amenazas y persecuciones de «bajas enemigas» propaladoras de mentiras para indisponer entre sí a las respectivas familias. Es un hecho, como se verá más adelante, que las relaciones familiares iban de mal en peor. De ahí los pasos cautelosos de la pareja de amantes.

Era recurrente en Petra lamentar la ausencia de «mi adorado Antonico» y subir a la finca familiar de La Dehesa «para ver si no me muero de tristeza por que es mucha la soledad que te tengo". Allí pasaba el tiempo en la espera de noticias suyas, «mirando el mar, sin poder descubrir una belita por pequeña que sea; parece que asta los Barcos se esmeran en disgustarme alargando sus biages» (13 de noviembre de 1843$)^{72}$. Antonio la tranquilizaba una y otra vez, prometiendo, si se mantenía sexy, las pequeñas expansiones lícitas del roce cuerpo a cuerpo anteriores al matrimonio (cosquillas, pellizcos, besitos) ${ }^{73}$. Así, el 5 de diciembre de 1843:

Balgate Dios muger, siempre te estas lamentando y siempre estas con esos malditos temores necios [...]. Tu procura tomar como otras veces tu leche de vacas, para tener el gusto de encontrarte tan gorda, cuando de el salto por alla. Mira que te haré muchas ruindades y es presiso que estés gorda, que estraño ahora el no estar siempre jugando contigo ${ }^{74}$.

El año 1844 transcurrió por senderos conocidos. Petra reprochaba a su novio que no le escribiera, interpretaba sus silencios como falta de amor, lamentaba que los barcos no entrasen y saliesen con mayor frecuencia y, a veces, se exaltaba hasta el punto de: "me quiero morir, te dejo y me voi á vivir á otro mundo, donde te aguardaré» (3 de marzo de 1844). Antonio se lo tomaba con paciencia: "no me escandalises... mira que si estas para morir, por que te quieres morir, es conveniente que digas en todo la verdad para que te salves y vivas despues conmigo en la gloria, allí en la quieta mancion de los espiritus... Con que, mi querida, no pensemos mas en morir. Tu engordate, distraete y no se mas que te diga» (17 de marzo de 1844) ${ }^{75}$.

${ }^{71}$ Esta carta no parece figurar en la nueva clasificación de fondos del Archivo de El Museo Canario.

72 ES35001 AMC, AP- 02405.

${ }^{73}$ Gay, Peter. La experiencia burguesa. De Victoria a Freud, vol. I: La educación de los sentidos. México D.F.: Fondo de Cultura Económica, 1992, p. 77.

${ }^{74}$ ES35001 AMC, AP- 02250.

75 ES35001 AMC, AP- 02415 y 02257. 
Y en otra ocasión (22 de mayo de 1844): «he quedado admirado de tus espabientos; muger no seas boba, no seas tan mimosa».

Del otoño de 1844 a la primavera de 1845 , en que la correspondencia conservada entre ambos concluye, la gran preocupación de Petra de las Casas Lorenzo fue el dinero que Antonio necesitaba reunir para afrontar los derechos de la titulación y otros gastos apremiantes en el final de su licenciatura. Petra y algunos familiares más empeñaron sus alhajas para aquel fin, mientras otros parientes se escaquearon con diversos pretextos. A nuestra protagonista, que parece llevar el peso de la colecta de los 230 duros necesarios, le indignó que solo Francisco de las Casas López, hermano de Antonio, fuese el «único pariente que tubo consideración y eso Dios sabe porqué» (6 de octubre de 1844) $)^{76}$.

El subrayado de arriba es de Petra y permite columbrar el choque entre los hermanos De las Casas López apenas fallecido el cabeza de familia Antonio de las Casas Álvarez, que, como veremos, marcará las relaciones familiares en lo sucesivo. Tal vez la explicación a esta presumible desavenencia se encuentra en el testamento paterno. Quiso asegurar que sus hijos Antonio y José María pudieran costearse hasta el final sus carreras de Derecho en caso de fallecimiento del progenitor... sin que se les descontase de su legítima, dando por supuesto que los demás herederos compartirían su punto de vista «de las bentajas que resultaran á sus demás hermanos de que lleguen á recibirse de Abogados $»^{77}$.

\section{APUNTES DOMÉSTICOS DEL MATRIMONIO DE LAS CASAS}

Antonio de las Casas López y Petra de las Casas Lorenzo se casaron el 30 de noviembre de 1847 en Santa Cruz de La Palma ${ }^{78}$. Fijaron su primer domicilio en la casa paterna de Antonio, en la calle Real (llamada O'Daly hacia el final de la década siguiente) compartiendo techo con su madre viuda y sus hermanos célibes Miguel, María del Pino, María Dolores, Juana y Federico ${ }^{79}$. Pocos años después, por el fallecimiento de la madre en $1852 \mathrm{y}$, un año antes, la mudanza de los hermanos a una vivienda en la calle Real de Santiago de la misma ciudad, el matrimonio se quedaría solo con su pequeńo hijo, una criada y una nodriza ${ }^{80}$.

El cabeza de familia recuperó por entonces el grueso cuaderno de cuentas de su padre, que este había utilizado para registrar las partidas de aguardiente compradas a muchos productores de la isla durante más de quince años. El registro paterno terminaba apenas consumida la tercera parte del cuaderno, de modo que su hijo mayor decidió aprovechar los ciento y pico folios restantes en blanco, sin

76 ES35001 AMC, AP- 02426.

77 AGP, PN, escribanía de Antonio López Monteverde, Santa Cruz de La Palma, 1840; testamento de don Antonio de las Casas Álvarez, f. 337 v.

78 APES, Matrimonios, Libro 9. ${ }^{\circ}(1822-1851)$, f. 253.

79 AMSCP, Padrón de habitantes de 1849, Caja 369.

${ }^{80}$ AMSCP, Padrón de habitantes de 1855, Caja 370. 
paginar, para anotar en desorden múltiples noticias relativas a sus intereses privados. Funciona a la manera de un dietario de ingresos y gastos de la casa, pero además asienta cuestiones particulares de la familia y fechas importantes para no olvidar: el óbito de su parentela, la escolarización del hijo o las pequeńas actividades económicas $^{81}$. Nos acerca a los asuntos domésticos cotidianos de esta familia decimonónica de Santa Cruz de La Palma.

La ubicación social de la familia De las Casas en el seno de la burguesía insular no había permanecido inmutable de una generación a la otra. Si la actividad mercantil del padre de nuestro protagonista logró afianzar a la familia en los sectores intermedios de la burguesía, su muerte prematura, endeudado, produjo en sus herederos un descenso del estatus alcanzado. De esta suerte, Antonio de las Casas López, abocado a la pérdida de patrimonio y al empobrecimiento, quiso evitar la debacle pero al precio de enfrentar a su familia (se verá en el capítulo siguiente).

Nuestro hombre pertenece a esa burguesía urbana canaria del siglo XIX que no era solamente comercial o industrial, o dedicada a las profesiones liberales como en este caso, sino que se caracterizaba por diversificar los ingresos económicos mediante la práctica de una o más de tales actividades junto a otras de tipo agropecuario y rentista ${ }^{82}$.

Antonio de las Casas López ejerció la abogacía en la década de 1850 y primeros años de la de 1860. Su actividad letrada comprendía desde pleitos civiles de menor cuantía hasta causas criminales en el Juzgado de Primera Instancia de La Palma. Según sus apuntes, no faltaron litigios sobre capellanías y patronatos, particiones de bienes, hurtos y robos, querellas por injurias, despojos y préstamos no devueltos, cuyas notas incluían también el nombre del cliente y los honorarios devengados. Llenó tres páginas solo con el listado de sus escritos legales, los clientes para cuyos pleitos los había redactado y el dinero cobrado en cada caso (mínimo 10, máximo 580 reales). Ejerció de manera más intensa en la primera mitad de los años $1850^{83}$ y en el trienio $1859-1861$.

No es posible aquí examinar la clientela de nuestro abogado (domicilio, estatus económico, filiación política...), lo que nos permitiría profundizar en su ambiente de sociabilidad en el trabajo y fuera de él. Sí sabemos algo de la relación

${ }^{81}$ ES35001 AMC, AP- 04141. Salvo indicación de lo contrario, la información expuesta en las páginas siguientes remite a esta misma fuente.

82 Véanse Millares Cantero, Agustín. «Notas para un estudio sobre la burguesía majorera en el tránsito del XIX al Xx». Anuario del Centro Asociado a la UNED de Las Palmas, n. ${ }^{\circ}$ (1979), pp. 75-139; Idem et al. «Hechos y figuras de la burguesía grancanaria: un esbozo de sus prácticas de clase». Anuario del Centro Asociado a la UNED de Las Palmas, n. 6 (1990), pp. 67-98.

${ }^{83}$ Uno de sus mejores clientes fue Antonio Cabezola Pérez Volcán de Mesa, propietario y vecino de la capital palmera, cuyos pleitos (impugnación de una herencia familiar; derechos sobre patronatos y capellanías) exijieron de nuestro abogado varios trabajos judiciales apreciados en 5947 reales hasta la hora de cambiar Cabezola su testamento en octubre de 1851. Letrado y cliente acordaron que el primero percibiría sus honorarios «según pudiera» abonarlos el segundo. Ahora, en este nuevo codicilo, Cabezola ordenaba terminar de pagarlos hipotecando sus bienes si fuera preciso. Consúltese AGP, PN, escribanía de Antonio López Monteverde, Santa Cruz de La Palma, 1851, ff. 291 v.-294. 
con sus colegas por las anotaciones antedichas. De entre todos, parece que tuvo más estrecha amistad con el letrado José Antonio Hernández Guerra, buen amigo de la universidad, mientras que sentía el mayor respeto por José Alejandro de Medina, doctor en Derecho (a través de él fue como se suscribió a El Faro Nacional en 1851 y a la Colección legislativa de España en 1856). Por contra, Silvestre Batista Abreu, veterano líder progresista local, era su gran adversario en lo profesional y en lo político.

Además de su domicilio en la calle Real capitalina, el abogado De las Casas poseía dos fincas rústicas en el barranco de Maldonado en Santa Cruz de La Palma, donde pasaba los veranos: una, de dos fanegadas, contigua a la ermita del Carmen; y la otra, su hacienda preferida de casi doce fanegadas. Como para nuestro abogado era imprudente fiar el porvenir solo a las ganancias obtenidas de su profesión, no tardó mucho tiempo en introducir la cochinilla en sus terrenos cuando esta comenzó a triunfar en la isla ${ }^{84}$. Plantó tuneras en cuatro canteros, las cuales semilló en septiembre de 1858 y logró las primeras cosechas en el verano del año siguiente (un quintal y seis libras en julio; un quintal y siete libras en agosto) ${ }^{85}$. Cultivó, asimismo, papas inverneras.

Más allá de las relaciones de parentesco, Antonio de las Casas López tendió a su alrededor una red social de estrechos vínculos socioeconómicos fundados en la amistad y el clientelismo político. De este cariz fue la entente duradera entre el hacendado José de Guisla y Pinto y nuestro abogado, relación que comenzó a finales de la década de 1840 cuando Guisla arrendó a De las Casas diversas fincas durante ocho años por 50 pesos anuales, con otros contratos entre ambos ventajosos para el abogado. Este, por su parte, pagaba las contribuciones del hacendado. Más tarde, Guisla fue el valedor ante la Real Audiencia de Canarias para el nombramiento de Antonio como juez de paz de la capital palmera, el 18 de febrero de 1861 (cargo que ocupó hasta 1863), frente a su colega y oponente Valcárcel, quien contaba con la ayuda de los terratenientes Vandewalle ${ }^{86}$.

Otros ingresos complementarios para la familia De las Casas fueron los intereses devengados a favor de Petra en su calidad de copropietaria del bergantín San Miguel, la administración de los bienes del cura Miguel Febles (a partir de noviembre de 1850), el alquiler de una lonja de su casa a personas de las clases populares

84 Pérez Hernández, José Eduardo. «Entre el ideal y la realidad. Discurso de la modernización y devenir económico en La Palma (1850-1900)». Boletín Millares Carlo, n. 22 (2003), pp. 73-74.

${ }_{85}$ No aparecen más anotaciones al respecto: o fue una experiencia efímera o el letrado dejó de registrar posibles cosechas posteriores en aquel cuaderno.

${ }^{86}$ Con toda probabilidad, se trata del abogado José María Valcárcel, casado con una Vandewalle, lo que explica el arropamiento de este apellido de largo abolengo insular. Sin embargo, esta vez la fuerza del parentesco no pudo con la fuerza clientelar que sustentaba a Antonio de las Casas López. Guisla y Pinto, cuyos apellidos remiten también a la vieja oligarquía palmera, parece reformular la práctica tradicional del patronazgo y el clientelismo, como ha apuntado el historiador Jesús Cruz para el caso de los notables madrileños, en aras de buscar «una comunidad de intereses» con la nueva burguesía capitalina. Véase Cruz, Jesús. Los notables de Madrid..., op. cit., p. 274. 
por un duro mensual ${ }^{87}$, y la cría de cabras, a medias con el hijo del sacristán de la parroquia de San Pedro Apóstol en Breńa Alta, y de una burra para el suministro de leche de la casa.

Según sus notas, Antonio de las Casas López, fiel a su mentalidad pragmática burguesa de bendecir el ahorro y anatematizar el derroche, apenas gastaba voluntaria y desinteresadamente de puertas afuera; nada al parecer en espectáculos públicos, ni en celebraciones festivas. Solo una vez participó en una suscripción ciudadana: a mitad de 1851 se suscribió con un tostón mensual para sostener a los enfermos de elefantiasis refugiados en las cuevas de Carías a las afueras de la ciudad, la cual mantuvo al menos hasta diciembre del mismo ańo. Pero tampoco entonces puede hablarse únicamente de caritativo desprendimiento, sino de pragmatismo, de nuevo, y de miedo, pues había que despejar el centro urbano de la presencia incómoda de aquellos infelices que pedían limosna en las calles principales y en los umbrales de las casas más ricas de la capital. La cuestión era «higienizar» la ciudad, en suma, por el temor a sufrir la grave epidemia de cólera morbo que mortificaba entonces a la isla de Gran Canaria.

De puertas adentro, el abogado De las Casas parecía seguir el mismo régimen de austeridad... hasta el feliz acontecimiento que cambió la situación. El 29 de octubre de 1854 nació Antonio, su primer y único hijo, bautizado el 24 de marzo de 1855 en la parroquia de El Salvador. Sorprende el tiempo transcurrido -casi siete años- entre la boda y el nacimiento del niño ${ }^{88}$, pero más todavía el intervalo hasta su bautizo, explicable quizá por tratarse de una criatura enfermiza. A partir de entonces, como se verá, los cuidados del niño y la atención del hogar multiplicaron los gastos: servicio doméstico ${ }^{89}$, médicos, escolarización, etc., lo cual se compadece con el aserto historiográfico de que la infancia pasó a ocupar gradualmente el centro de la vida familiar en el siglo xIx; que nunca antes cada niño, máxime si había

87 «Debe tio Antonio Cachimbo, desde este dia 16 de junio de 1851, pagar dos rta. por la lonja y traer un barril de agua todos los días = Pagó 5 fiscas hoy 19 de sept.; pagó 2 fiscas hoy 3 de octubre».

${ }^{88}$ Es probable que se trate de un hecho natural, pero de ser una decisión voluntaria habría varios motivos: por una parte, una doble espera, es decir, a pasar lo peor de la depresión económica de aquellos ańos en la isla y a quedarse solos en la casa tras la marcha de los hermanos y la muerte de la madre de Antonio (con el añadido de cumplir con el luto de rigor); por otra, el temor a que su retońo naciese imperfecto, anormalidad sobre la cual planeaba la sombra del pecado y el deshonor, pues había la creencia en la Santa Cruz de La Palma del Ochocientos de que los hijos nacían con alguna tara en los matrimonios de próximo parentesco. Consúltese Bethencourt Alfonso, Juan. Costumbres populares canarias de nacimiento, matrimonio y muerte. Santa Cruz de Tenerife: Cabildo Insular de Tenerife, 1985, p. 177.

${ }^{89}$ Se ha señalado que «la hora de la criada» llegaba en situaciones en que «el mundo ilustrado de la burguesía perdía su aplomo. Así ocurría en general siempre que la naturaleza iba por sus fueros, es decir, en los nacimientos, las enfermedades y la muerte. Al haber desterrado de su experiencia verbal y visual todas esas manifestaciones de la vida ligadas a la corporeidad, la burguesía dependía de personas expertas». Véase Budde, Gunilla Friederike. «La criada», en Frevert, Ute y Haupt, Heinze-Gerhard (eds.): El hombre del siglo XIX. Madrid: Alianza, 2001, p. 206. 
nacido en el seno de las clases privilegiadas, recibió más atenciones y cuidados de sus padres, y más recursos económicos, educativos y afectivos ${ }^{90}$.

Por cierto que las pocas páginas del cuaderno citado que figuran escritas por la mano de Petra de las Casas se sitúan, aproximadamente, el año antes de dar a luz a su único hijo y tienen relación con este hecho. Nos muestra a una mujer enamorada de su marido e ilusionada con la idea de la maternidad; pero también supersticiosa, aficionada a los juegos de futurología y predispuesta a dejarse seducir por las nociones de su destino que aquellos supuestamente le revelaban ${ }^{91}$.

En noviembre de 1855, nuestro abogado inició el apunte sistemático de cuantas sirvientas y amas de cría pasaron por la casa en los ocho años siguientes. $\mathrm{Si}$ antes de aquella fecha hay muy poco anotado sobre el tema, desde entonces su número es altísimo, porque más de cincuenta chicas distintas entraron de criadas (apenas cuatro o cinco varones). Parecen demasiadas para esta familia de tres miembros que, según los padrones municipales, nunca tuvo más de dos criadas a la vez, o bien una criada y una nodriza. Puede ser que la exigencia del matrimonio De las Casas fuese grande (Antonio trataba de buscar a sus domésticas en entornos de confianza), y que algunas de aquellas jóvenes campesinas pecasen de rudas y respondonas ${ }^{92}$ (el letrado cita dos apodos: María demonio y Francisca diablo fuerte), pero no es menos cierto la abundancia de muchachas palmeras a quienes la crisis económica de entonces empujaba a la capital insular en demanda de empleo; para muchas un estadio intermedio en su proyecto último de emigrar a $\mathrm{Cuba}^{93}$.

En efecto, del lado insular, la economía atravesaba una profunda depresión, más sensible a partir de 1835; el capitalismo agrario había acentuado la proletarización del campesinado, lo que generó un excedente de fuerza de trabajo. Del lado antillano, Cuba vivía una sostenida expansión económica y se había convertido en atractivo mercado de trabajo bajo contrata mediante el acuerdo entre la Junta de Fomento y los armadores y capitanes del tráfico canario-cubano, cuyo resultado

90 Guttormsson, Loftur. «Las relaciones paternofiliales», en Kertzer, David y BarbaGLI, Marzio (comps.): Historia de la familia europea..., op. cit., v. II, p. 388.

${ }_{91}$ El primero de estos juegos consistía en «Preguntas hechas al oráculo, según las reglas del libro de los destinos», y la entretuvo durante el verano de 1853. Petra formulaba su pregunta y sacaba a continuación una carta o ficha jeroglífica con la respuesta. Por supuesto, respuestas complacientes; esto es: que ella superaría sus presentes desgracias; que en el año venidero sería dichosa; que el objeto de su amor sería su mayor tesoro; que la persona amada le correspondía sinceramente y (¡ay!) que ella llegaría a la vejez. El segundo juego, posterior aunque sin fecha, pronosticaba, en líneas generales, cómo sería la vida futura del bebé según en cual de los treinta días siguientes a la luna nueva naciera. El tercer juego era otro pronóstico similar que, sucintamente, retrataba el carácter moral y la suerte futura de los niños en función del día de la semana en que se produjera su nacimiento.

92 Contar al menos con una sirvienta era necesario para que una familia pudiera afirmar su pertenencia al estatus burgués en el siglo xix. Pero no valía cualquier criada. Era requisito universal que estas trabajadoras fuesen sumisas y calladas ante las órdenes de sus señores. Consúltese BudDE, Gunilla Friederike. «La criada», op. cit., pp. 188-189.

93 Pérez Hernández, José Eduardo. «Mujeres de Santa Cruz de La Palma en la emigración a Cuba (1850-1870)", en XVI Coloquio de Historia Canario-Americana (2004). Las Palmas de Gran Canaria: CD-R editado por el Cabildo de Gran Canaria, 2006, pp. 763-791. 
más llamativo, entre otras ventajas, fue la reducción del flete del pasaje a la mitad (de 40 a 20 pesos fuertes, quedando así el coste del viaje del migrante bajo contrata equiparado al del pasajero por cuenta propia en tercera clase; el flete del migrante peninsular adulto era en cambio de 45 pesos fuertes). Los enganchadores de la Junta de Fomento recorrían las islas reclutando gente para sus expediciones eficazmente, porque además existía una cadena migratoria tradicional. Así, entre 1851 y 1854 , varios cientos de isleñas llegaron a Cuba con contrato específico para el servicio doméstico: jóvenes solteras entre 15 y 24 años en su inmensa mayoría. Su vínculo contractual duraba 8-9 meses y después eran libres de buscar un mejor acomodo en el mercado laboral cubano. Tenerife, La Palma y La Gomera fueron las islas que más capital humano aportaron en este sentido ${ }^{94}$.

En las notas del abogado De las Casas encontramos señales de que las criadas se iban por propia decisión tanto o más que se las despedía (en estos casos emplea el verbo mandar: «se la mandó»). Lo más habitual era que sus sirvientas, de las cuales muchas salían sin cobrar nada al parecer, permanecieran una o dos semanas en la casa, seguido de aquellas que estaban entre tres semanas y dos meses; muy pocas superaron este tiempo ${ }^{95}$. Con la mayoría acordaba un peso mensual -el servicio doméstico percibía este mismo salario en La Palma cincuenta años atrás- ${ }^{96}$, aunque ya desde los primeros años 1860, cuando repunta la economía insular, Antonio de las Casas, posiblemente siguiendo la corriente general, consolidó en un duro tales emolumentos ${ }^{97}$.

Por su parte, las amas de cría aparecen apuntadas en el cuaderno un año y medio después del nacimiento del pequeño Antonio, si bien el prenotado padrón de habitantes de 1855 indica que el recurso de la lactancia mercenaria, todavía practicada entre los sectores privilegiados de la época, parece haber entrado en escena desde el principio de la maternidad de Petra. Con más razón al padecer ella ictericia, según las numerosas visitas de los médicos Pérez Pino y Kábana anotadas por nuestro abogado a lo largo de 1856, para cuya curación aplicaba tanto las recetas

94 Macías Hernández, Antonio. Revisiones y provocaciones..., op. cit., pp. 340-348. La real orden de 7 de septiembre de 1856 puso freno a esta fiebre migratoria. En Canarias, la cochinilla iniciaba su expansión y la tarratenencia necesitaba que la mano de obra permaneciera aquí [Ibidem, p. 365].

95 Era rasgo general de las trabajadoras domésticas en la Europa del Ochocientos la gran movilidad laboral, más elevada en las grandes ciudades pero nada desdeñable también en las medianas y pequeñas. El cambio de servicio era estimulado además por las ofertas prometedoras con que las familias burguesas solían arrebatarse las criadas [BudDE, Gunilla F. «La criada», op. cit., pp. 209210]. No tenemos datos, empero, que avalen este comportamiento burgués en Santa Cruz de La Palma, de manera que la presumible movilidad de las sirvientas en estos primeros años 1850 tenía, como quedó dicho, un destino más apetecible en La Habana y otras ciudades cubanas.

96 Pérez Hernández, José Eduardo. «Mujeres de Santa Cruz de La Palma...», art. cit., p. 769. El salario mensual de las sirvientas emigradas a Cuba bajo contrata era de 84,55 reales en las mismas fechas; Véase Macías Hernández, Antonio. Revisiones y provocaciones..., op. cit., p. 350.

97 Pocas veces Antonio de las Casas López incluyó ropa y calzado como parte del sueldo, o adelantó dinero a cuenta del mismo a petición de las interesadas para que éstas adquiriesen tales prendas o para otras necesidades. 
de la botica como los remedios de la medicina natural; verbigracia, su interés por la yerba llamada morianga. Como en el caso de las criadas, el trasiego de nodrizas fue notable: casi una veintena de marzo de 1856 a julio de 1857. Muy pocas cobraron su salario mensual íntegro (habitualmente 3 ó 4 pesos), pues cerca de la mitad duró menos de una semana y la otra media alcanzó dos o tres semanas. Únicamente dos nodrizas, «María Gutiérrez la del Morroco» y «Carolina», merecieron la confianza prolongada del matrimonio De las Casas.

El cuaderno recoge también que el matrimonio recurrió a las amas de cría en dos momentos posteriores: noviembre de 1857 y julio de 1858 . Desde esta última fecha el niño fue destetado definitivamente y basó su alimentación en la leche de burra y de vaca, la primera suministrada por una tal «tia Meregilda», a razón de medio tostón diario, y la segunda a cargo de «la muger Vinagre». La distorsionada percepción de que lo saludable era una criatura sobrealimentada pudo ser fatal para Antonio hijo, como para muchos pequeños de su tiempo (la mortalidad por indigestión o gastroenteritis y por el desconocimiento todavía de la pasteurización de la leche animal). Pero sobrevivió, y poco antes de cumplir seis años, en octubre de 1860, empezó su andadura escolar en la escuela de amiga: «casa de la hija de Antonio Casas" ${ }^{98}$.

\section{PLEITOS DE FAMILIA99}

\subsection{EN EL NOMBRE DEL PADRE}

Antonio de las Casas Álvarez cometió el mayor error de su vida a comienzos de la década de 1840 , de fatal consecuencia para sí y posterior repercusión negativa en su familia. Padecía de gastroenteritis crónica y decidió automedicarse con el que por entonces era popular pero malhadado método Le Roy, de cuyo abuso resultó

98 Parece tratarse de don Antonio de las Casas González, bien instruido «en las artes de escribir y aritmética», cabo del regimiento provincial de la isla durante una década (desde los 16 años), escribiente, actuario en tribunales de justicia, recaudador de impuestos, procurador [AMSCP, Caja 610, Expedientes e instancias varios; Santa Cruz de La Palma, 17 de febrero de 1831], secretario municipal en San Andrés y Sauces y, más tarde, en Breńa Alta. Vivía en la capital palmera, en la calle Mataviejas número 12, en 1860. Pero, ¿a qué hija se refiere? Tenía cuatro hijas con él de su primer matrimonio (Calista, de 30 años; María Gracia, de 27; Antonia, de 25; Cipriana, de 23; todas ellas solteras y con conocimentos de lectura y escritura); y una hija de sus segundas nupcias, Escolástica, de 12 años, que también sabe leer y escribir [AMSCP, Padrón de habitantes de 1860, Caja 371] Esta última podría ser la amiga que empezó a enseñar al pequeño Antonio. Pocos años después, De las Casas González pasó a desempeñar, entre 1864 y 1876, el puesto de maestro de escuela en el pueblo de Breña Alta. Escolástica de las Casas Bethencourt llevaba el gusanillo de la profesión docente, porque obtuvo el título de maestra, regentando largamente la escuela pública de nińas de Breńa Alta a partir del 27 de diciembre de 1879. Fue la primera maestra de escuela pública de nińas de aquel municipio.

99 Es preciso apuntar que, si bien los litigios a los que nos referiremos en las páginas siguientes pueden ser considerados los más significativos en la familia De las Casas, hubo más pleitos y ramificaciones de pleitos que alcanzaron a otros parientes De las Casas López, De las Casas Lorenzo y 
afectado su sistema nervioso con la parálisis de su lengua, vejiga y piernas, y la disminución progresiva de sus facultades intelectuales ${ }^{100}$. La perlesía lo dejaría incapacitado del todo dos años después, en el otoño de 1843, falleciendo el año siguiente. Sus hijos Antonio y José María de las Casas López, estudiantes en la Universidad de San Fernando de La Laguna, habían solicitado meses antes al juez Ossuna la declaración de incapacidad para su padre y el nombramiento de un curador ejemplar responsable del enfermo y administrador de sus intereses, cosa que hizo en la persona del escribano Antonio López Monteverde una vez visto el dictamen favorable de dos médicos ${ }^{101}$.

La enfermedad del cabeza de familia cambió para siempre la vida de Francisco de las Casas López. Dado que Antonio y José María estaban ausentes, y Tomás y Federico eran menores de edad (sus hermanos), Francisco, que había cursado estudios náuticos en Santa Cruz de Tenerife, decidió no emprender la carrera de marino, como piloto del bergantín San Miguel, y sí tomar las riendas del negocio paterno en la capital palmense: una gran tienda de ropa. Ya no dejó la profesión mercantil (enseguida al frente de su propio establecimiento) hasta su muerte en 1870. Pero aquella etapa en que llevó la tienda del padre, más o menos con la supervisión de este antes de su total incapacidad, y después en solitario, le traería problemas en el futuro por las cuantiosas deudas que quedaron a la muerte del comerciante Antonio de las Casas Álvarez.

Los acreedores se cernieron sobre la familia reclamando sus créditos, resultado de los géneros pedidos a distintas casas comerciales de la provincia ${ }^{102}$. Los hermanos Antonio y José María, ya flamantes abogados, pusieron en marcha de común

López Monteverde. En ellos no entra el historiador tanto por insuficiente documentación al respecto cuanto por no hacer más prolijo el artículo.

100 Algunos ańos antes, don Antonio Tassara, apoderado del rico hacendado palmero don

Felipe Massieu y Tello en Sevilla, advertía a este, en varias cartas, lo siguiente: «... no van los 7 de la medicina curativa de Le Roi por estar prohibida su venta y circulación, por la multitud de desgracias ocurridas con su uso...» (5 de julio de 1830). Y ante la insistencia de su poderdante desde La Palma, reiteraba: «... Por mi conducto nunca tendrá V. la obra de Le-Roi, se lo digo a V. así francamente, y le suplico no la lea nunca; he perdido amigos a quien [sic] apreciaba, por haber usado su método curativo, y no puedo permitir que otro que me tiene dadas tantas pruebas, y hasta quiero, sufra la misma desgracia...» (10 de noviembre de 1830). No pudo disuadir a Massieu, de manera que Tassara hubo de conseguirle la obra por conducto reservado: «... Está comprado el exemplar de casos prácticos de Le Roi como V. me pide [...] ygualmente cuando regrese Orta [un capitán de barco] llevará en su baúl los 3 de la medicina purgativa [...] mediante a que $V$. insiste en su remisión, [...] pero sentiré sea causa de ocasionar a V. y a sus amigos alguna desgracia, con el uso de la medicina del jarave de Fierabras que lo sanaba todo...» (28 de diciembre de 1830). Véase AGP, Fondo Lugo Viña-Massieu, Correspondencia, Caja 9.

${ }_{101}$ ES35001 AMC, AP- 03891: Expediente de inhabilitación de don Antonio de las Casas Álvarez (1843).

102 Adeudaba 1720 pesos a Lebrún y Davidson, casa comercial de Santa Cruz de Tenerife; 467 pesos a Diego Swanston \& Cía., del comercio de Las Palmas de Gran Canaria; y 119 pesos a Francisco García, comerciante de Santa Cruz de Tenerife. Consúltese ES35001 AMC, AP-01815, 01816, 03886, 03887, 03889, 03901, 03962, 05310 y 05326. 
acuerdo, según refleja su correspondencia, una estrategia poco escrupulosa para la salvaguardia del patrimonio familiar ${ }^{103}$. El primero, en la capital palmera; el segundo, buen genealogista y bibliófilo, en la ciudad de La Laguna, donde fallecería en 1894. Antonio, en particular, obtuvo la representación legal de sus hermanos menores e hizo todo lo posible para impedir la subasta judicial de los bienes familiares. Se aferró con «delirio» -fue su expresión- a la posesión de su finca favorita de Maldonado y buscó la ayuda de sus amigos políticos ${ }^{104}$. Entendamos su mentalidad: más allá de los bienes materiales, el pleito judicial amenazaba incluso con liquidar a la familia misma, su estructura y respetabilidad, por lo cual había que preservarla al precio que fuera. El endeudamiento era un pesado baldón para cualquier familia que se preciaba de respetable en la época ${ }^{105}$. Así pues, para ganar tiempo asumió de inicio las deudas paternas y solicitó generoso plazo a sus acreedores para saldarlas. Cuando las maniobras dilatorias ya no sirvieron y las casas de comercio acudieron a los tribunales, sin dejar de obstaculizar el curso de la acción judicial, trató de incriminar a un solo miembro de su familia; aquel precisamente que se mostraba de frente al asumir su parte en el entuerto familiar.

Hay indicios que permiten pensar en una enemistad entre los hermanos Antonio y Francisco de las Casas, que pudo incubarse en los ańos de la grave enfermedad de su padre, pero no solo por esta causa. Durante los primeros años $1840 \mathrm{se}$ consolidó en La Palma la escisión de los liberales entre los Cangrejos y los Carboneros, o progresistas y moderados, siglas que dominarían por décadas la lucha política insular ${ }^{106}$. Pues bien: Santa Cruz de La Palma fue la fortaleza progresista de la isla bajo el mando de la familia Batista, incluso en el tiempo de la década moderada en el país (1844-1854). Lo más fácil habría resultado girar en la órbita hegemónica, pero nuestro abogado, y antes que él su padre, militaba firme en la facción política más conservadora. Francisco, sin embargo, se dejaba querer y aconsejar por cierto

103 Pérez Hernández, José Eduardo. Las personas de valer..., op. cit., pp. 188-189.

${ }^{104}$ En este sentido, en 1854 envió cartas solicitando o agradeciendo favores a diversas personas: el juez de primera instancia de Santa Cruz de La Palma, Eugenio Perea; el marqués de Guisla e hijo; Juan Lorenzo Ferrer, y su colega grancanario Antonio López Botas.

${ }^{105}$ Ya tenía bastante la familia De las Casas con la mácula de sus antepasados magos (campesinos incultos) del valle de Aridane, pero, además, llovía sobre mojado respecto del sambenito de las deudas. Un episodio ocurrido pocos ańos antes ilustra con claridad la severidad del tribunal de la opinión pública. En 1839, en el acaloramiento de una trifulca verbal entre el presbítero Manuel de las Casas Lorenzo, a la sazón capellán de la Armada Nacional, y el marino Miguel Calderón, este espetó a su adversario que al menos él construía su barco con el sudor de su frente (De las Casas se había burlado del buque, todavía en el astillero, y de su dueño, comparándolo con una "penca de tuna»), mientras que el San Miguel "fue hecho con robos y con deudas». Y a la réplica provocadora del nada manso eclesiástico que le ofrecía dinero para concluir la embarcación y se vanagloriaba de ser más y mejor que el otro, Calderón respondió, hablando no solo de sí mismo, "que no era nacido en la Banda, que era nacido en la ciudad y que mis abuelos nunca habían andado con mulos». El clérigo De las Casas Lorenzo demandó a Calderón y no se avino, como sí hizo el demandado, al dictamen conciliador de los hombres buenos en el juicio de conciliación celebrado en la alcaldía capitalina. Véase AMSCP, Caja 769, Juicios de conciliación (1820-1844), ff. 19-20.

106 Pérez Hernández, José Eduardo. Las personas de valer..., op. cit., pp. 109-113. 
prohombre de las filas progresistas, al parecer el clérigo Miguel Batista Abreu ${ }^{107}$. De este modo, por traicionar la tradición de la familia en política (así lo habría enfocado Antonio), su hermano se ganaría la etiqueta de oveja negra, enemigo culpable de la ruina familiar, fuera ello verdad o no, en cuyo caso siempre sería el chivo expiatorio idóneo.

Antonio de las Casas López urdió su versión de los hechos para enfrentarse a las demandas de los acreedores de la familia, según la cual su hermano Francisco era el único responsable de la «estafa y ruina» del negocio paterno. Le acusó de aprovechar la incapacidad de su padre, actuando en su nombre, para desfalcarle seis o siete mil pesos en tres ańos con el objeto de levantar su propia tienda (una mercería), ello deduciendo mil pesos de los gastos domésticos y los estudios universitarios de sus hermanos. Las deudas contraídas con conocidas casas de comercio isleñas, superiores a dos mil pesos, eran suyas también, pero pretendía cubrirlas con bienes patrimoniales de la familia (aún proindivisos). Citaba: la venta de la tienda paterna y de algunos terrenos en Los Llanos a los suegros de Francisco en 1851, forzando que su madre firmara una falsa escritura pública de deuda para justificar lo segundo ${ }^{108}$; la subasta de las fincas rústicas de Santa Cruz de La Palma, oponiéndose Francisco -sin éxito-a que Antonio salvara la finca más apreciada por medio del ardid de utilizar a un testaferro de su confianza. Enfatizó además que, hasta la fatal enfermedad, su padre mantuvo con solvencia la actividad mercantil sin disminuir su capital ${ }^{109}$.

Para disgusto de nuestro abogado, su madre y sus hermanos no corroboraron la versión antedicha en los tribunales. La primera, retirada en el campo la mayor parte del tiempo, conoció por Antonio que él mismo elevaría a nombre de ella cierto escrito para contrarrestar la demanda de la casa comercial Lebrún, pero no supo de su contenido entonces, ni lo ratificó luego, toda vez que decía desconocer las actividades mercantiles de su marido y de su hijo Francisco. Tampoco María del Pino suscribió la versión de su hermano, alegando ignorancia de los hechos que se atribuían a Francisco. Por su parte, Miguel de las Casas López desmintió la explicación de Antonio: era verdad -declaró- que su hermano Francisco había abierto su propia tienda en vida de su padre, pero este voluntariamente le daba cartas que abrían puertas a sus relaciones mercantiles (Antonio consideraba falsas esas cartas, pues aseguraba no reconocer la firma y la rúbrica de su padre), merced a las cuales

107 Antonio escribió al juez Eugenio Perea, el 20 de mayo de 1854, sobre los presuntos tejemanejes de su hermano Francisco, y señaló una influencia: «el mismo clérigo Batista que es su director».

${ }^{108}$ La escribanía de su tío Antonio López Monteverde (un aliado leal en caso de necesidad) era el sitio indicado para albergar las supuestas escrituras falsas. Puede serlo la venta de la tienda por parte de Francisco de las Casas López a sus suegros, José Antonio Camacho de Justa y Petra Fernández Tańo, como pago de tres aparentes préstamos, que totalizan 4497 pesos (el precio exacto de la compraventa), percibidos de aquellos en 1846 y 1850 . Muchos ańos después, en 1864, en una nota ańadida al margen de dicha escritura, los suegros dijeron haber recibido de su yerno la suma indicada y declararon que la tienda pertenecía solo a Francisco. Véase AGP, PN, escribanía de Antonio López Monteverde, Santa Cruz de La Palma, 1851, ff. 136-137 v.

109 Sobre las cuentas de Antonio de las Casas Álvarez entre 1839 y 1842, consúltese ES35001 AMC, AP- 03962 . 
las casas de comercio de la provincia fiaban suministros a su hijo, cuyos importes abonaba luego al cabeza de familia para su entrega a las casas acreedoras (no devolvería Francisco sino una parte del total, según Antonio) y, en concreto, la deuda reclamada por Lebrún \& Davidson era de su difunto padre, fruto de los gastos para el sostén de la familia y para dar carrera a Antonio y José María ${ }^{110}$.

Claro que a los acreedores poco les importaba esta discrepancia familiar. En sus papeles no figuraba otro deudor que Antonio de las Casas Âlvarez y tras su muerte, su viuda e hijos, de suerte que contra toda la familia continuaron los pleitos judiciales. En 1850, los demandados trataron de parar la acción de Swanston \& Cia. obligándose a pagar el crédito con aquella firma y las costas mediante la hipoteca de la casa familiar, pero la finca urbana estaba ya demasiado exprimida para resultar viable: la mitad sujeta a la dotación que había servido de congrua para la ordenación sacerdotal de Miguel de las Casas López, y ofrecida además en idéntica maniobra a la casa Lebrún como seguro de pago de su crédito ${ }^{111}$. Sería el último y vano intento de detener lo inevitable.

El juzgado de primera instancia de Santa Cruz de La Palma falló a favor de las casas comerciales acreedoras en sucesivas sentencias a principios de la década de 1850, decretando, en el caso Lebrún, el embargo de bienes de la viuda e hijos De las Casas. El golpe judicial quizá aceleró la muerte de María Dolores López Monteverde, acaecida el 17 de agosto de $1852^{112}$. La viuda había asistido no solo a la amenaza del patrimonio familiar, sino también a la desunión de sus hijos. Puede que pasando factura a sus hermanos por no apoyar su defensa judicial, Antonio desalojó de su casa a María de los Dolores, María del Pino y Miguel de las Casas López en junio de 1851, aduciendo que no pagaban su parte proporcional en las contribuciones (ello le valió una reprimenda severa de su hermano José María desde Tenerife ${ }^{113}$ ).

Nuestro abogado no había podido impedir la subasta judicial de la casa y de las tierras de Santa Cruz de La Palma, pero encontraría la manera de hacerse con las fincas rústicas al margen de los demás herederos. Tras dos años de pública

${ }_{110}$ Acaso una razón para que Antonio de las Casas endosara la culpa de lo sucedido a su hermano era no admitir que quizá todo comenzó con su onerosa carrera universitaria. Pero, ¿puede descartarse cualquier responsabilidad de Francisco de las Casas en la ruina familiar, a tenor de su necesidad de dinero en 1852 que lo impulsó a cierto negocio arriesgado, y al hecho de tener endeudado su establecimiento mercantil cuando contrajo segundas nupcias al final de su vida?

111 Archivo Histórico Provincial de Las Palmas: Audiencia, Procesos, Expediente 5.698. Autos seguidos en el Juzgado de Primera Instancia de La Palma por Diego Swanston \& Cía contra la Viuda e Hijos de don Antonio de las Casas Álvarez (1850).

112 Antonio de las Casas López anotó en su prenotado cuaderno doméstico (folio 69): «El 17 de agosto martes a la tardecita de 1852, falleció mi madre [...], y fue sepultada al otro dia 18 por la mañana en el Campo Santo de esta Ciudad. Me vinieron a ver, de duelo, las personas siguientes: 1. ${ }^{\text {er }}$ - Día, del entierro: el vicario D. José Donoso; el licenciado D. José Antonio Hernández; D. José Miguel Cabezola y Antonio Pérez (a) Cabrilla. 2.- Día: el Marqués D. Luis Vandewalle, el licenciado D. José María Valcárcel; el promotor D. José Medina [de quien curiosamente anota sus palabras al despedirse: «siento mucho su disgusto y mande usted en que pueda servirle»]; D. Antonio Barroso y D. Cipriano Valcárcel». Véase ES35001 AMC, AP- 04141.

113 Pérez Hernández, José Eduardo. Las personas de valer..., op. cit., p. 190. 
subasta, un único licitador, Antonio Ortega Rodríguez, que actuaba como la persona interpuesta de De las Casas, remató ambas fincas de Maldonado y la de La Dehesa en 1854 por menos dinero de su valor líquido en el mercado (seis mil reales, entregados a la casa Lebrún) ${ }^{114}$.

\subsection{Los intereses del bergantín San Miguel}

Podría pensarse que el letrado De las Casas era aficionado a las cosas de la mar, a juzgar por el seguimiento que hizo del San Miguel (barco propiedad de la familia de su mujer) en su cuaderno de notas. Apuntó sus viajes anuales a Cuba entre 1850 y 1855: fechas de salida y llegada, carga, número de pasajeros e incidencias del viaje. No siempre disponía de todos los datos, pues sus informes no provenían de los dueños del buque, sino de la propia observación y de noticias indirectas ("dicen», «se dice»). Una de aquellas notas explicaba, por ejemplo, que el San Miguel había zarpado el 17 de enero de 1852 para La Habana llevando 150 pasajeros, cada uno al precio de una onza de oro, menos 25 o 30 de cámara que pagaban el doble; que el 27 de mayo, una vez pasada la cuarentena en Riga, donde al parecer cargó 600 fanegas de millo, el bergantín había entrado en la bahía de Santa Cruz de La Palma con 46 pasajeros, 21 de los cuales abonaron de cuatro a cinco onzas cada uno por viajar en la cámara ${ }^{115}$.

En realidad, Antonio de las Casas López perseguía la parte de los beneficios de aquellos viajes que tocaba a su esposa Petra, pues no se fiaba de cómo su suegra y sus cuñados dirigían la empresa familiar: un círculo cerrado basado en la confianza recíproca, del cual estaba excluido Antonio. Exigía, pues, conocer al detalle las cuentas de todas las expediciones americanas del San Miguel, única forma de comprobar si su esposa percibía lo que en derecho le correspondía. Como sus parientes fueron reacios a variar de método empresarial, nuestro hombre, poco después de casarse, les demandaría judicialmente, año tras ańo, sin aparente resultado inmediato. De ahí que al mismo tiempo procurase averiguar, a su manera, lo que deseaba saber acerca de las ganancias del barco.

Nuestro protagonista acudía al juicio de conciliación tan pronto como el San Miguel rendía sus viajes. Siempre dirigía sus demandas contra José Miguel, Nicolás o Miguel de las Casas Lorenzo, porque amén de copropietarios del buque eran también los capitanes, y siempre sucedía que reclamaba a los demandados exhibir las cuentas del último viaje, a fin de que el reparto de su utilidad entre la viuda María de la Encarnación Lorenzo y sus nueve hijos no ofreciese dudas respecto de su equidad. Pero solamente obtenía excusas y largas, a saber: no disponían de las cuentas sin tener primero las de los consignatarios de fuera de la isla sobre los fletes cobrados, faltaba por entregar parte de la carga, o alguno de los capitanes del viaje

114 AGP, PN, escribanía de José María Salazar, Santa Cruz de La Palma, 1854, ff. 183 v.-195.

115 ES35001 AMC, AP- 04141. 
de ida o de vuelta estaba ausente. El tribunal se pronunciaba a favor del demandante y emplazaba a los demandados a que efectuasen lo exigido, cosa que no satisfacía al abogado De las Casas (casi nunca hubo avenencia por su parte) ${ }^{116}$.

En 1852, es de suponer que harto de la tenacidad de su primo, José Miguel de las Casas Lorenzo le instó a poner el dinero proporcional para llevar a cabo la reparación del barco o, en caso de no hacerlo, arriesgarse a la expropiación dominical del bergantín. El abogado demandó a los tres hermanos citados porque, para atender esta obligación, era preciso que aquellos exhibieran las cuentas sin demora de diversos viajes del San Miguel a lo largo del decenio anterior. Claro está se topó con la eterna barrera, esto es: que desde el principio los hermanos acordaron relevarse de toda cuenta formal, confiando todos en lo que cada cual hacía en las expediciones que capitaneaba. Los demandados reprocharon además a su hermana Petra, y por ende al demandante, que lo producido por el bergantín no solo había servido para saldar las deudas contraídas en su fabricación, sino también para que la familia pudiese sostenerse con decencia y comodidad, incluida Petra, quien disfrutó de su parte en los beneficios, también del haber materno, a costa «de los sudores y sacrificios de todos sus hermanos». Era muy embarazoso, concluyeron, formar las cuentas de viajes realizados tiempo atrás, tildando a Antonio de «un mal compañero e inorante [sic] en las operaciones que necesita la administración y gobierno de una nave». Una vez más, el juez de paz resolvió que los demandados debían cumplir con las cuentas, con especificidad de las cantidades que hubiera percibido el demandante después de su matrimonio, abonando además sumas determinadas según el tiempo que se tardara en su cumplimiento o bien para eximirse de toda cuenta (diez mil reales) ${ }^{117}$.

Como no hubo conformidad en los juicios de conciliación arriba expuestos, muy posiblemente el pleito continuó en las instancias judiciales superiores, pero no tenemos por el momento constancia documental de ello.

En 1856, con vistas al pago de la contribución correspondiente, el ayuntamiento de Santa Cruz de La Palma fijó al público el repartimiento de la misma "para purificarlo de agravios», regulando el rendimiento del barco San Miguel, de la carrera de América, en 30000 reales. La viuda Lorenzo y sus hijos varones, sintiéndose precisamente agraviados, protestaron de inmediato y pidieron la rebaja del producto del buque a 15000 reales anuales. Argumentaron que el bergantín, a sus 18 ańos de vida, no rendía lo mismo que en los primeros ańos de sus empresas en viajes «buenos y venturosos», pues ahora la nave pedía costosas reparaciones de casco, aparejos y útiles. Más aún al compararse con otro barco de la competencia, el bergantín goleta Franco - del cual Sebastián Arozena era su capitán y copropietario-, «acabado de flotar sobre las aguas lleno de vida», capaz de hacer dos viajes al año a América frente al único anual del San Miguel y, sin embargo, estimado

116 AMSCP, Juicios de conciliación, Caja 770; 23 de octubre de 1849, 29 de agosto de 1850, 11 de septiembre de 1850 y 25 de octubre de 1851 .

117 Ibidem; 12 de agosto de 1852. 
su rendimiento en 26400 reales por la junta pericial ${ }^{118}$. Tanta reserva familiar con las cuentas del barco podía dar lugar a una situación como la descrita, ello en el supuesto de que no se trataba de una torticera manera de chinchar a los enemigos políticos desde el poder municipal.

El remozado buque de la familia De las Casas Lorenzo sobrevivió a sus achaques de viejo y puede decirse que se extinguió casi a la par que lo hacían los miembros de la sociedad mercantil «Las Casas Hermanos» (por el deceso de los mismos: José Miguel, en 1878; Antonio, en 1880; Andrés, en 1881; Miguel, en 1888...).

\section{EPÍLOGO}

Con la década de 1860 llegó la tragedia para el matrimonio De las Casas. Petra enfermó la noche de Año Nuevo de 1861 y murió a la una menos cuarto de la madrugada del 24 de enero a causa de un ataque apopléctico. Antonio, que también anotó el óbito de su mujer en su cuaderno, comentó que había acudido mucha gente al entierro de Petra en el cementerio de la ciudad en la tarde del día siguiente ${ }^{119}$.

Poco podía imaginar nuestro abogado que a no mucho tardar la tumba se abriría también para él. La perlesía, al igual que le ocurriera a su padre, acabó con su vida en la tarde del 17 de mayo de 1866, a la edad de 51 ańos, precedida su muerte por un largo tiempo de sufrir perlático al cuidado de su hermana Dolores, a cuya casa fue trasladado dos meses después del primer ataque y donde falleció. Por mano de su cuñado y curador ejemplar Severiano González Guerra (1829-1875), propietario, concejal del consistorio capitalino, escribano de actuaciones judiciales, la penosa etapa postrera de Antonio de las Casas López quedó registrada en el citado cuaderno familiar del finado:

Vivió perlático tres años y 19 días, pues se encontró atacado el dia 28 de abril de 1863 por su primo don Nicolás de las Casas al solicitarlo para cierta pregunta de derecho, al tercero ataque se postró en cama y estubo sin lebantarse 5 meses, pues fue el 5 de diciembre de 1865, quedando imposibilitado de hablar; al siguiente dia de su fallecimiento se le dio sepultura en el cementerio acompañandolo el venerable Beneficio, cuatro capellanes y música; le fue mucha gente a su entierro, y el 23 de dicho mes y año [mayo de 1866] se le hiso el oficio de honras en la parroquia de El Salvador...

Por ironías de la vida, la finca grande de Maldonado (seis hectáreas y una casa de dos pisos) que tanto empeño en conservar puso nuestro hombre, salió a subasta pública apenas unos días antes de fallecer aquel, por auto judicial y a ins-

118 AMSCP, Expedientes e instancias varios (1851-1860), Caja 614.

119 ES35001 AMC, AP- 04141. Así mismo APES, Defunciones, Libro 14, f. 181. Por entonces, según el padrón de 1860, la familia De las Casas López vivía en la calle de Vandale, número 2, con una sirvienta. 
tancias de María Dolores de las Casas López, su curadora ejemplar y cuidadora, con cuya venta saldaría la elevada deuda (855 pesos) contraída para atender los gastos de la enfermedad de su hermano ${ }^{120}$.

Es posible que los apuntes de lengua y ortografía del cuaderno doméstico familiar, sacados al parecer de un libro de texto, remitan a los estudios de primaria del pequeño Antonio de las Casas y de las Casas, cuya minoría de edad pasó con sus tíos Severiano y Dolores. Andando el tiempo llegó a ser marino en su juventud y luego procurador en el Juzgado de Primera Instancia del distrito de Santa Cruz de La Palma, ciudad en donde contrajo matrimonio con María Magdalena Remón Calero el 13 de julio de $1887^{121}$.

\section{CONCLUSIONES}

El matrimonio De las Casas, que tan prematuramente descendió a la tumba, ha sido, con sus parientes cercanos y antepasados, el objetivo de este estudio por la singular circunstancia de pervivir una extraordinaria documentación privada sobre ellos.

El apellido palmero De las Casas representa a la burguesía agraria consolidada mediante su vínculo como arrendatarios con la oligarquía terrateniente insular en el valle de Aridane en la segunda mitad del siglo XvinI. La siguiente generación fija su domicilio en la calle principal de la capital, Santa Cruz de La Palma, y se afinca en su demarcación y lugares aledaños. Dedicada al comercio de tienda y de exportación con barco propio, accede a las regidurías de su ayuntamiento y a los mandos de la milicia; y en su tercera generación también al ejercicio de las profesiones liberales.

Aunque constituye el paradigma de ascenso social de una nueva burguesía que de agraria deriva en urbana, comercial y liberal, y que no olvida el apego rentista a la tierra, el ahorro y la inversión económica diversificada, sin embargo, mantiene comportamientos de la sociedad estamental de tiempos pasados; actitudes que chocan con el modelo ideal burgués de prácticas de clase. Así, frente a la igualdad de oportunidades y el mérito individual, subsisten con fuerza los recursos del parentesco, la amistad, el padrinazgo y el clientelismo. También aún pervive el viejo concepto de linaje familiar, pues la familia es la depositaria del honor y la nombradía del apellido; con discreción, todo es válido para afianzar su sacrosanto patrimonio material y simbólico (el prestigio y calado social: quizá el lector haya observado, por ejemplo, el orgullo satisfecho con que nuestro protagonista apunta en las notas necrológicas de su familia que a sus entierros acude mucha gente). Y, por lo mismo, todo es válido para no perderlo ante la amenaza del endeudamiento y el escándalo de las desavenencias internas.

\footnotetext{
120 ES35001, AMC, AP- 03953 y 03988.

121 ES35001, AMC, AP- 01974.
} 
Pero asimismo la modernidad está presente no tanto porque una viuda, a mediados de la centuria decimonónica, se ponga al frente de los negocios familiares, cuanto por la irrupción del sentimiento amoroso en cohabitación con la sólida persistencia del enlace endogámico y la estrategia de cálculo en las alianzas matrimoniales burguesas. El amor, vivido a la moda o sensibilidad romántica en boga, asoma aquí, aunque subrepticio, quizá porque no trastorna o contraviene con lo establecido.

Recibido: 14-1-2021; ACEPTAdo: 15-4-2021 
